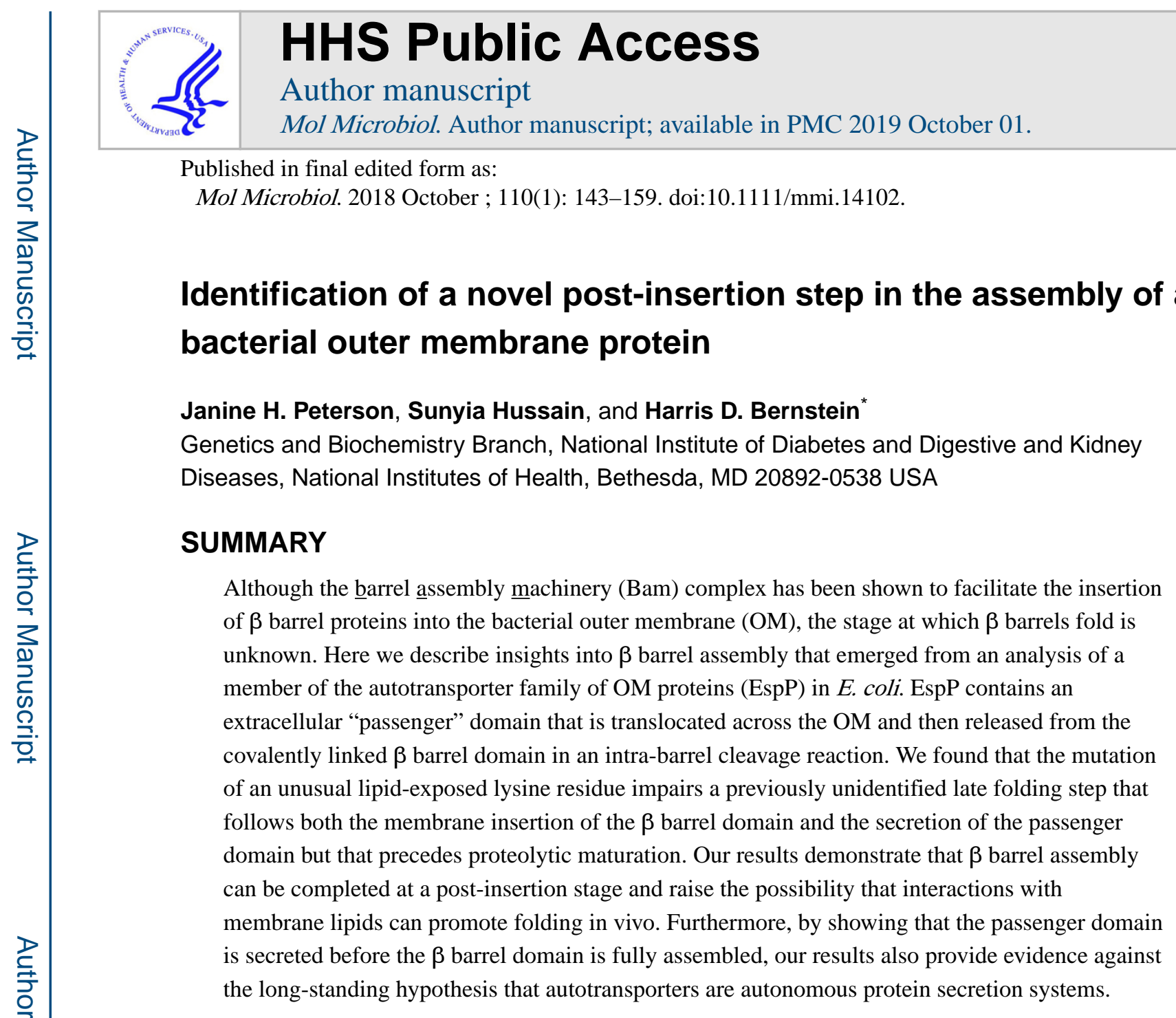

\title{
ABBREVIATED SUMMARY
}

An unusual lipid-exposed lysine residue promotes a previously unidentified step in the folding of the $\beta$ barrel domain (membrane spanning domain) of a bacterial autotransporter. This step follows both the insertion of the $\beta$ barrel domain into the outer membrane, which is catalyzed by the barrel assembly machinery (Bam) complex, and the secretion of the extracellular (passenger) domain. The results show that $\beta$ barrel assembly can be completed at a post-insertion stage.

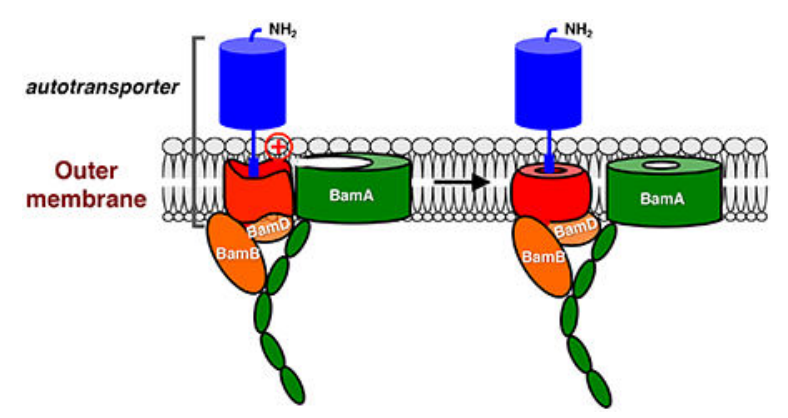

*For correspondence. harris_bernstein@nih.gov; Tel. (+1) 301402 4770; Fax (+1) 3014969878. AUTHOR CONTRIBUTIONS

HDB designed the study and wrote the paper. All authors contributed to the acquisition, analysis and interpretation of the data. 


\section{Keywords}

autotransporter; $\beta$ barrel; Bam complex; outer membrane; protein folding

\section{INTRODUCTION}

Although most integral membrane proteins contain $\sim 20$ residue a-helical membrane spanning segments, the vast majority of proteins that reside in the outer membrane (OM) of Gram-negative bacteria contain an unusual membrane spanning segment known as a $\beta$ barrel. $\beta$ barrels are essentially amphipathic $\beta$ sheets wrapped into a closed cylindrical structure that is held together by hydrogen bonds between the first and last $\beta$ strands. Unlike $a$-helical membrane spanning segments that are hydrophobic and consequently readily partition into lipid bilayers, $\beta$ barrels cannot reside stably in the OM until they fold and expose a hydrophobic outer surface. Despite sharing a common architecture, OM proteins (OMPs) are structurally diverse in part because their $\beta$ barrels range greatly in size from 8 $26 \beta$ strands (Fairman et al., 2011; Dong et al., 2014; Qiao et al., 2014). Some $\beta$ barrels are empty while others contain an embedded segment (or even a non-covalently linked protein), and some form homo-oligomers. Furthermore, some OMPs contain periplasmic or extracellular domains attached to the $\beta$ barrel domain.

Several steps in the assembly of OMPs have been clearly identified. OMPs are initially translocated across the inner membrane (IM) through the SecYEG complex. Once in the periplasm, OMPs interact with a variety of molecular chaperones including Skp and SurA (Chen and Henning, 1996; Lazar and Kolter, 1996; Rouvière and Gross, 1996; Schäfer et al., 1999) that presumably keep them in an assembly-competent conformation. Subsequently their insertion into the $\mathrm{OM}$ is catalyzed by a heterooligomer called the Bam (barrel assembly machinery) complex (Voulhoux et al., 2003; Wu et al., 2005). In E. coli the Bam complex consists of BamA, an integral OMP that contains five periplasmic POTRA (polypeptide transport-associated) domains and four lipoproteins (BamB-E) that bind to the POTRA domains (Wu et al., 2005; Kim et al., 2007; Sklar et al., 2007). Although the composition of the Bam complex in different Gram-negative bacteria is variable, both BamA and BamD are highly conserved and essential for viability (Malinverni et al., 2006; Wu et al., 2007; Webb et al., 2013). The finding that in the presence of SurA the purified Bam complex is sufficient to mediate the assembly of OMPs into proteoliposomes indicates that no other factors are absolutely required for the insertion reaction (Hagan et al., 2010).

Although the structure of the entire Bam complex was recently solved (Bakelar et al., 2016; Gu et al., 2016; Han et al., 2016; Iadanza et al., 2016), the mechanism by which it catalyzes the membrane insertion of OMPs is unknown. Based on structural studies and molecular dynamics (MD) simulations it has been proposed that OMPs pass through the pore of the BamA $\beta$ barrel in an unfolded conformation and then insert into the lipid bilayer in a stepwise fashion through a lateral gate formed upon the transient separation of the first and last $\beta$ strands (Noinaj et al., 2013). This model is supported by evidence that disulfide bonds that lock the BamA $\beta$ barrel into a closed conformation create lethal phenotypes or inhibit Bam complex function in vitro (Noinaj et al., 2014; Iadanza et al., 2016). In an alternative 
model it has been proposed that the Bam complex facilitates the membrane integration of folded or partially folded $\beta$ barrels by perturbing the lipid bilayer (Noinaj et al., 2013). This model is supported by evidence that at least some OMPs begin to fold prior to membrane integration (Ieva et al., 2008; Lee et al., 2016; Sikdar et al., 2017), that BamA lowers the kinetic barrier for OMP insertion imposed by lipid head groups (Gessmann et al., 2014), that BamA exerts a greater catalytic effect on OMP folding in thicker bilayers (Schiffrin et al., 2017), and that BamA is highly dynamic in liposomes (Doerner and Sousa, 2017). The crystal structure of the Bam complex shows that the POTRA domains and the four lipoproteins form a ring below the BamA $\beta$ barrel. While MD simulations suggest that the ring structure might induce movement of substrates by a rotational motion (Gu et al., 2016), they do not show whether they pass through the pore of the BamA $\beta$ barrel or directly into a distorted lipid bilayer. Furthermore, it is unclear if cellular factors other than the Bam complex play a secondary role in promoting the assembly of OMPs. Indeed there is evidence that lipopolysaccharide (LPS), a unique glycolipid that forms the outer leaflet of the OM, stimulates the assembly of at least some OMPs (Bulleris et al., 2003; Arunmanee et al., 2016).

One family of OMPs called autotransporters have proven to be valuable in studies of OMP assembly because they are especially amenable to experimental analysis. These proteins contain a large N-terminal extracellular ("passenger") domain in addition to a C-terminal $\beta$ barrel domain (Dautin and Bernstein, 2007). The two domains are connected by an $\alpha$-helical linker that traverses the $\beta$ barrel pore. Passenger domains typically fold into an unusual repetitive structure known as a $\beta$ helix and often mediate a virulence function in pathogenic bacteria. Although the sequence of the $\mathrm{C}$-terminal domains are highly divergent, they fold into nearly superimposable 12-stranded $\beta$ barrels (Oomen et al., 2004; Barnard et al., 2007; van den Berg, 2010; Zhai et al., 2011; Gawarzewski et al., 2014). Several reliable assays can be used to monitor discrete stages of autotransporter assembly in vivo. Integration of these proteins into the OM, for example, can be assessed by following the exposure of the passenger domain on the cell surface. Furthermore, the completion of assembly of the SPATE (serine protease autotransporters of E. coli) family of autotransporters can be assessed by monitoring the proteolytic release of the passenger domain. This autocatalytic reaction occurs only after the passenger domain is translocated across the OM (Dautin et al., 2007; Ieva and Bernstein, 2009). To complement in vivo experiments, autotransporter assembly can be studied in a cell-free assay that requires the addition of only the Bam complex and SurA (Roman-Hernandez et al., 2014). Autotransporters are also of particular interest because the mechanism of passenger domain translocation has been the subject of a long-standing controversy. Over 30 years ago it was proposed that these proteins are autonomous secretion systems in which completely folded $\beta$ barrel domains transport covalently linked passenger domains across the OM (whence the name "autotransporter") (Pohlner et al., 1987). Despite the accumulation of evidence that the Bam complex plays a role in the translocation reaction and other findings that have strongly challenged this proposal (Bernstein, 2015), however, the self-transport model has persisted (Fan et al., 2016).

In this report, we describe a significant new insight into OMP assembly that emerged from the analysis of an autotransporter mutant. Our study was motivated by the observation that 
the $\beta$ barrel of EspP, a well-characterized $~ 135 \mathrm{kD}$ SPATE produced by E. coli O157:H7, contains three lipid-exposed lysine residues (Fig. 1A). This was a surprising discovery because charged residues are infrequently found on the outer surface of $\beta$ barrels and the introduction of lipid-exposed arginine residues into $\beta$ barrels can inhibit OMP assembly (Ulmschneider and Sansom, 2001; Jackups and Liang, 2005; Jimenez-Morales and Liang, 2011; Chamberlain and Bowie, 2014; Peterson et al., 2017). We found that replacing one of the lysine residues (K1280) with other amino acids delayed the proteolytic maturation of EspP. Interestingly, our results indicate that the mutations only affected the cleavage reaction indirectly by perturbing a previously undetected assembly step that follows both the insertion of the $\beta$ barrel into the $\mathrm{OM}$ and the secretion of the passenger domain but that precedes proteolytic processing. The data provide a "proof of concept" that the assembly of a $\beta$ barrel can be completed at a post-insertion stage. As a corollary, by showing that the passenger domain of EspP is secreted before the $\beta$ barrel domain is fully assembled, our results also corroborate other evidence that autotransporters are not self-contained protein secretion systems.

\section{RESULTS}

\section{A lipid-exposed lysine residue is required for efficient EspP assembly}

Although charged residues are underrepresented on the outer surface of bacterial $\beta$ barrel proteins, those that have been found are often located near the extracellular side of the OM (Jackups and Liang, 2005; Slusky and Dunbrack, 2013). Consistent with this observation, a recent study showed that the introduction of surface exposed arginine residues into EspP or another E. coli OMP (OmpLA) by site-directed mutagenesis affects assembly in a highly position specific fashion (Peterson et al., 2017). Arginine residues located close to the aqueous interface produced no effect or a very minor effect on assembly, whereas those located near the middle of the $\beta$ barrel produced major assembly defects. Based on these observations, we hypothesized that the lipid-exposed lysine residues in the EspP $\beta$ barrel, which are located relatively close to the periplasmic or extracellular side of the OM (Fig. 1A), would not significantly affect assembly. It is striking, however, that K1280 is conserved in all members of the SPATE family and that a basic or large polar residue is located at the same position in strand $\beta 11$ in a wide variety of distantly related autotransporter $\beta$ barrels and predicted autotransporter $\beta$ barrels (examples are shown in Fig. 1B). Furthermore, a basic residue is conserved at the position that is equivalent to K1212 throughout both the SPATE family and the loosely related pertactin family of Bordetella pertussis autotransporters (Dautin et al., 2007).

To explore the function of the surface-exposed lysine residues in the EspP $\beta$ barrel, we first determined if mutating these residues would affect the efficiency or kinetics of assembly. Based on the expectation that mutations that affect any step in assembly delay or impair all later steps, we monitored the cleavage of the protein into discrete passenger and $\beta$ barrel domains that occurs at the end of the assembly pathway. To determine if the mutations specifically affect the targeting of EspP to the Bam complex or an early stage of $\beta$ barrel insertion that is required to trigger the initiation of passenger domain translocation (Pavlova et al., 2013a), we also used protease shaving to monitor the exposure of the passenger 
domain on the cell surface. In characterizing the mutations we exploited the finding that most of the passenger domain is dispensable for assembly because secretion proceeds in a $\mathrm{C}$ to N-terminal direction (Ieva and Bernstein, 2009; Junker et al., 2009). To maximize the probability of detecting even minor defects, we initially analyzed a truncated form of EspP (EspP $\Delta 1$ ) that assembles slightly more rapidly and synchronously than the full-length protein (Skillman et al., 2005). AD202 were transformed with a derivative of pTRC99a that encodes wild-type $\operatorname{EspP} \Delta 1$ or a mutant under the control of the trc promoter. Cells were grown in M9 medium and subjected to pulse-chase labeling after the addition of IPTG. Half of each sample was untreated while the other half was treated with proteinase $\mathrm{K}(\mathrm{PK})$. Immunoprecipitations were then conducted using an antiserum against a C-terminal EspP peptide. The untreated samples were used to monitor the accumulation of the cleaved $\sim 30$ $\mathrm{kD} \beta$ barrel domain. The treated samples were used to determine the fraction of $\operatorname{proEspP} \Delta 1$, the $\sim 43 \mathrm{kD}$ precursor form of the protein in which the two domains are covalently attached, that was exposed on the cell surface.

Surprisingly, we found that the mutation of residue K1280 markedly delayed the completion of protein assembly. While $50 \%$ of the wild-type EspP $\Delta 1$ molecules were cleaved in $\sim 30$ sec, the cleavage of half of the K1280A, K1280L and K1280Y mutant molecules required $\sim 3$ min (Fig. 2A, lanes 1-5; Fig. 2C). All three mutants were processed at about the same rate as a previously described slow cleavage mutant (N1023Q) that contains a glutamine in place of the catalytic asparagine residue (Fig. 2A and Fig. 2C, triangles; see Dautin et al., 2007). The replacement of N1023 with a slightly larger glutamine residue slows the nucleophilic attack on the polypeptide backbone that is mediated by its amide group. Representative data are shown, but very similar results (some of which are illustrated in other Figures) were obtained in multiple experiments. The results are striking given that the K1280A, K1280L and K1280Y mutations all increase the hydrophobicity of the $\beta$ barrel surface and might have been predicted to accelerate assembly. The introduction of a K1280Q mutation into EspP $\Delta 1$ also slowed assembly, but had a more modest affect than the other mutations (Fig. 2A and Fig. 2C, crosses). This observation implies that the presence of a lysine (or at least a basic residue) at position 1280 is required to maximize the efficiency of EspP assembly. Because none of the mutations significantly affected the exposure of the passenger domain on the cell surface (Fig. 2A, lanes 6-10 and Fig. 2B), K1280 must facilitate a relatively late step in assembly that occurs after the integration of the $\beta$ barrel into the OM has been initiated. Unlike the K1280A mutation, the K1212A mutation did not affect EspP assembly (data not shown).

To obtain further insight into the function of residue K1280, we next introduced K1280A and K1280L mutations into full-length EspP and a very short EspP derivative. The mutations did not affect the surface exposure of the full-length $\sim 105 \mathrm{kD}$ passenger domain, but delayed proteolytic processing to about the same degree as they delayed the proteolytic processing of EspP $\Delta 1$ (Fig. S1). Due to the relatively slow cleavage of the mutant proteins, a previously described $\sim 4 \mathrm{kD}$ PK fragment of proEspP that consists of the $\beta$ barrel domain plus a $\sim 17$ kD C-terminal folded segment of the passenger domain (Ieva and Bernstein, 2009; Peterson et al., 2010; Ieva et al., 2011) persisted at later time points (Fig. S1A, lanes 6-10). These observations, together with the finding that the mutations did not affect the appearance of a previously described $\sim 80 \mathrm{kD}$ PK-resistant N-terminal passenger domain fragment (Fig. S2, 
lanes 6-10; see Peterson et al., 2010), indicates that the mutations do not affect either the translocation or folding of the full-length passenger domain. Finally, the observation that K1280 mutations exerted a very similar effect on the proteolytic processing of $\operatorname{EspP} \Delta 5$, a derivative that contains only a 26 residue passenger domain fragment that remains inside the $\beta$ barrel and is never secreted (Pavlova et al., 2013a), provided additional evidence that the mutations do not impair passenger domain export (Fig. S3).

\section{Mutations of EspP residue K1280 perturb assembly of the $\beta$ barrel domain}

Given that residue K1280 is located on the surface of the EspP $\beta$ barrel domain far away from the intra-barrel cleavage site (Barnard et al., 2007), we hypothesized that this residue is required for a previously unidentified assembly step that follows the insertion of the $\beta$ barrel into the $\mathrm{OM}$ and the secretion of the passenger domain but that precedes proteolytic processing. Consistent with this notion, we found that cells that overproduce EspP $\Delta 1(\mathrm{~N} 1023 \mathrm{Q})$ grow normally but that cells that overproduce EspP $\Delta 1(\mathrm{~K} 1280 \mathrm{~A})$ have a mucoid phenotype on LB agar (Fig. 3). The results suggest that overproduction of the K1280A mutant causes a defect in the structure or integrity of the OM that, like similar perturbations, induces capsule biosynthesis (Whitfield, 2006). In any case, the distinct phenotypes provided the first indication that the K1280A and N1023Q mutations affect different steps in the EspP assembly pathway.

A comparison of the properties of proEspP $\Delta 1(\mathrm{~K} 1280 \mathrm{~A})$ and proEspP $\Delta 1(\mathrm{~N} 1023 \mathrm{Q})$ isolated from the $\mathrm{OM}$ provided direct evidence that the mutation of the lysine residue perturbs the folding of the $\beta$ barrel domain rather than the cleavage reaction per se. Initially we pulse labeled cells that produce a version of EspP $\Delta 1(\mathrm{~K} 1280 \mathrm{~A})$ or EspP $\Delta 1(\mathrm{~N} 1023 \mathrm{Q})$ that contains an N-terminal HA tag and conducted a 1 min chase. We then incubated cell membranes with the detergent n-dodecyl- $\beta$-maltoside (DDM) at $4^{\circ} \mathrm{C}$ overnight and performed immunoprecipitations with an anti-HA antiserum. Presumably because proEspP $\Delta 1(\mathrm{~N} 1023 \mathrm{Q})$ underwent slow autocatalytic cleavage during the overnight incubation, a substantial amount of free $\sim 14 \mathrm{kD}$ passenger domain was immunoprecipitated from the sample that contained this mutant (Fig. 4). In contrast, most of the proEspP $\Delta 1(\mathrm{~K} 1280 \mathrm{~A})$ remained intact. The results suggest that while proEspP $\Delta 1(\mathrm{~N} 1023 \mathrm{Q})$ was properly folded and, like other slow cleavage mutants, remained enzymatically active in detergent solution (Dautin et al., 2007), proEspP $\Delta 1$ (K1280A) was unable to fold into a cleavage-competent structure after its extraction from the OM.

We next used a limited proteolysis approach to probe the folded state of proEspP $\Delta 1(\mathrm{~K} 1280 \mathrm{~A})$ and proEspP $\Delta 1(\mathrm{~N} 1023 \mathrm{Q})$ further. Initially cells were pulse labeled and subjected to a $1 \mathrm{~min}$ chase and then permeabilized using lysozyme/EDTA. DDM was added to solubilize membrane proteins and cell extracts were treated with various amounts of trypsin or PK. Immunoprecipitations were then conducted using an anti-EspP C-terminal peptide antiserum. After the addition of $1-10 \mu \mathrm{g} / \mathrm{ml}$ trypsin, a prominent $\sim 40 \mathrm{kD}$ polypeptide was observed in cells that produced EspP $\Delta 1$ (N1023Q) (Fig. 5, $2^{\text {nd }}$ gel, o). A small amount of a $\sim 33 \mathrm{kD}$ polypeptide also appeared as the trypsin concentration was increased (Fig. $5,2^{\text {nd }}$ gel, oo). Likewise, a strong $\sim 35 \mathrm{kD}$ band was observed in the presence of $1 \mu \mathrm{g} / \mathrm{ml}$ PK (Fig. 5, $2^{\text {nd }}$ gel, *). A slightly smaller band that decreased in intensity was 
observed at higher PK concentrations. These protease-resistant polypeptides were presumably derived from the pro form of the protein because they are larger than the free $\beta$ barrel domain. Consistent with this prediction, the same fragments were observed in cells that produced the non-cleavable EspP $\Delta 1$ (N1023A) mutant (Fig. 5, bottom gel; Dautin et al., 2007). In contrast, no polypeptides larger than the free $\beta$ barrel domain were observed in cells that produced the EspP $\Delta 1$ (K1280A) mutant (Fig. 5, top gel). Furthermore, when pulselabeled cells were subjected to a longer chase and solubilized membrane proteins were treated with $1 \mu \mathrm{g} / \mathrm{ml}$ trypsin or PK, prominent 35-40 kD polypeptides that disappeared as proEspP $\Delta 1$ was cleaved were seen in cells that produced EspP $\Delta 1(\mathrm{~N} 1023 \mathrm{Q})$ but not those that produced EspP $\Delta 1$ (K1280A) (Fig. 6). Taken together, the results strongly suggest that the K1280A mutation delays passenger domain release indirectly by delaying the folding of the $\beta$ barrel domain into a compact, enzymatically active conformation.

Despite the evidence that K1280 mutations slow a late step in the EspP assembly pathway that is required for proteolytic processing, two observations indicate that the mutations do not prevent the $\beta$ barrel domain from eventually folding into a native conformation. Like the $\beta$ barrel of EspP $\Delta 1(\mathrm{~N} 1023 \mathrm{Q})$, the $\beta$ barrel of EspP $\Delta 1$ (K1280A) was relatively resistant to digestion with $1-5 \mu \mathrm{g} / \mathrm{ml}$ trypsin or $1-10 \mu \mathrm{g} / \mathrm{ml}$ PK in detergent solution (Figs. 5-6). PK treatment released a small amount of a characteristic $\sim 15 \mathrm{kD}$ C-terminal fragment from the $\beta$ barrel domain of both mutant proteins (Figs. 5-6, $\Delta$ ). Furthermore, like the $\beta$ barrel domain of wild-type EspP, the $\beta$ barrel domains of $\operatorname{EspP}(\mathrm{N} 1023 \mathrm{Q}), \operatorname{EspP}(\mathrm{K} 1280 \mathrm{~A})$ and EspP(K1280L) were highly resistant to SDS denaturation and migrated rapidly on SDSPAGE unless heated to a high temperature (Fig. S4; Barnard et al., 2007; Pavlova et al., 2013a). Although significant unfolding of the $\beta$ barrel domains that contain a K1280A or K1280L mutation was observed at a slightly lower temperature $\left(\sim 75^{\circ} \mathrm{C}\right.$ vs. $\left.\sim 80^{\circ} \mathrm{C}\right)$, this very subtle effect may simply reflect a difference in SDS binding due to the loss of a positively charged amino acid.

\section{The mutation of EspP residue $\mathrm{K} 1280$ affects a post-insertion step}

Several lines of evidence indicated that EspP residue K1280 facilitates an assembly step that occurs after the $\beta$ barrel domain is positioned within the OM but not fully integrated into the lipid bilayer as a freely diffusing and natively folded polypeptide. First, PK treatment of cells that produced wild-type EspP $\Delta 1$, EspP $\Delta 1$ (N1023Q) or EspP $\Delta 1$ harboring a K1280 mutation after pulse-chase labeling generated $\mathrm{a} \sim 33 \mathrm{kD}$ C-terminal fragment of proEspP $\Delta 1$ at early time points that diminished as the passenger domain was released by proteolytic cleavage (Fig. 2A, lanes 6-10). This fragment, which has been observed previously (Ieva et al., 2008; Skillman et al., 2005), contains the $\sim 30 \mathrm{kD} \beta$ barrel domain plus a $\sim 25$ amino acid passenger domain segment that is embedded inside the $\beta$ barrel prior to proteolytic maturation. Because a fragment of this size can be generated only if the passenger domain residues that emerge from the top of the $\beta$ barrel are accessible to $\mathrm{PK}$, the results imply that $\mathrm{K} 1280$ is not required for the rapid exposure of the $\operatorname{EspP} \beta$ barrel to the environment.

Analysis of an EspP $\Delta 1$ derivative that contains an insertion in one of the extracellular loops of the $\beta$ barrel [EspP $\Delta 1$ (L3ins); Fig. 1A] also indicated that K1280 does not play a role in early stages of the membrane integration process. Although the EspP $\beta$ barrel domain is 
normally resistant to PK digestion, previous work has shown that a 20 amino acid insertion in loop 3 sensitizes it to cleavage following its exposure on the cell surface (Ieva et al., 2011). To examine the effect of the K1280A mutation on the exposure of loop 3, AD202 transformed with a plasmid encoding EspP $\Delta 1$ (L3ins) or EspP $\Delta 1$ (K1280A/L3ins) were subject to pulse-chase labeling. Half of the cells were treated with PK, and immunoprecipitations were performed using an anti-EspP C-terminal peptide antiserum. Consistent with previous results (Ieva et al., 2011), the loop 3 insertion itself delayed an early step in the membrane integration of the $\beta$ barrel domain that is required for the initiation of passenger domain translocation (Fig. 7, top gel, lanes 1-5). Nevertheless, PK cleaved loop 3 as it was exposed and led to the production of a $\sim 14 \mathrm{kD} \mathrm{C}$-terminal fragment (Fig. 7, top gel, lanes 6-10; "PK fragment A"). Only a small amount of the PK fragment was visible in pulse-labeled cells, but a larger amount was observed after a 1 min chase. Presumably because a conformational change accompanies the proteolytic maturation of EspP, PK fragment A gradually disappeared and a very slightly smaller C-terminal fragment derived from the cleaved $\beta$ barrel domain ("PK fragment B") appeared (for clarity the two PK fragments are enlarged in Fig. S5). As expected, the combination of the loop 3 insertion and the K1280 mutation delayed assembly further (Fig. 7, bottom gel, lanes 1-5). The presence of the point mutation, however, did not delay the accumulation of PK fragment A (Fig. 7, bottom gel, lanes 6-10). By reporting on the status of loop 3, this finding provides direct evidence that K1280 promotes a step that follows the initial movement of the $\beta$ barrel into the OM.

Finally, site-specific crosslinking experiments provided evidence that the K1280A mutation affects a post-insertion step that is required for the completion of $\beta$ barrel assembly. In these experiments the photoactivatable amino acid analog p-benzoyl L-phenylalanine (Bpa) was incorporated at residue 1214 in the $\beta$ barrel domain of full-length $\operatorname{EspP}(\mathrm{K} 1280 \mathrm{~A})$ and $\operatorname{EspP}(\mathrm{N} 1023 \mathrm{Q})$ using a previously described amber suppression method (Farrell et al., 2005). This amino acid is located close to the periplasmic side of the $\beta$ barrel and has been shown to interact with BamD during EspP assembly (Ieva et al., 2011; Pavlova et al., 2013a; Peterson et al., 2017). Following pulse-chase labeling and UV irradiation, immunoprecipitations were performed using anti-BamD and anti-EspP antisera. Crosslinking products that contained the pro form of the two mutants and BamD were detected, but the proEspP(K1280A)-BamD product persisted for a longer period of time (Fig. 8 and Fig. S6). Very consistent crosslinking patterns were observed in multiple experiments (Fig. S7). These results suggest that the K1280A mutation causes a delay in the assembly of the $\beta$ barrel domain that in turn slows its release from the Bam complex. Indeed a prolonged interaction of the K1280A mutant with the Bam complex might hinder the binding of incoming client proteins and explain the mucoid phenotype that we observed when the protein was overproduced (Fig. 3).

In an effort to determine the mechanism by which residue K1280 facilitates the assembly of the EspP $\beta$ barrel, we tested the hypothesis that it mediates an important intermolecular or intramolecular interaction. Given its location near the cell surface, we initially surmised that K1280 might function by forming a salt bridge with an electronegative surface cavity located in the distal part of the BamA $\beta$ barrel (Ni et al., 2014). The observation that the acidic residues that are clustered in the cavity are not required for efficient EspP assembly, 
however, was inconsistent with this notion (Fig. S8A). We also hypothesized that K1280 might accelerate assembly by forming a salt bridge with a phosphate group of LPS, but we found that EspP assembled normally in a $r f a P$ - strain that lacks the inner core phosphates (Yethon et al., 1999) (Fig. S8B). Furthermore, when we examined the assembly of EspP $\Delta 5$ into proteoliposomes that contain the purified Bam complex, we found that EspP $\Delta 5$ (N1023Q) was assembled relatively slowly (presumably due to a delay in proteolytic maturation) but that EspP $\Delta 5(\mathrm{~K} 1280 \mathrm{~A}$ ) was assembled as rapidly as wild-type EspP $\Delta 5$ (Fig. S9). This observation provided additional evidence that K1280 does not mediate a key interaction between EspP and either the Bam complex or lipid-associated phosphate groups and also suggested that the residue does not form a critical intramolecular bond. Instead, the results suggest that $\mathrm{K} 1280$ participates in a reaction that is not reproduced by the in vitro assay. To explore the function of this residue further, we also introduced a K1280E mutation into EspP $\Delta 1$. We predicted that if K1280 forms either an intermolecular or intramolecular salt bridge, then the mutation would create a charge repulsion that strongly impairs assembly. In contrast, however, we found that the mutation exerted a smaller effect on assembly than the K1280A mutation (Fig. 9). The finding that lysine, glutamine and glutamate all promote more efficient assembly than hydrophobic residues suggests that the function of residue 1280 depends more on hydrophilicity than positive charge.

An important clue about the function of residue K1280 emerged from the fact that most members of the pertactin family and a subset of other autotransporters contain a lipid facing basic or large polar residue in strand $\beta 11$ slightly closer to the cell surface (Fig. 10A). In light of this observation, we examined the effect of a K1280Y/A1282K double mutation that mimics the sequence of pertactin on EspP $\Delta 1$ assembly. Despite the altered location of the lysine residue, the A1282K mutation partially suppressed the assembly defect created by the K1280Y mutation (Figs. 10B-C). The data show that a lipid facing lysine residue located near, but not at exactly the same position as K1280, can still enhance $\beta$ barrel assembly. Taken together with the aforementioned results, this finding raises the intriguing possibility that the presence of a lipid facing large hydrophilic residue positioned near the extracellular side of strand $\beta 11$ promotes the folding of the EspP $\beta$ barrel by perturbing the local membrane environment rather than by forming a specific interaction with another hydrophilic molecule.

\section{DISCUSSION}

In this study we identified a novel late step in the assembly of a bacterial autotransporter that occurs after its $\beta$ barrel domain is positioned within the OM (but not fully integrated into the lipid bilayer) and its passenger domain is secreted. Initially we found that the mutation of an unusual lipid-exposed lysine residue in EspP (K1280) slows proteolytic processing, but further analysis revealed that the delay was an indirect consequence of a defect in an earlier assembly step. Genetic and biochemical experiments as well as site-specific crosslinking and Bam complex-mediated in vitro assembly assays all showed that the properties of K1280 mutants can be clearly distinguished from those of a previously described catalytic (slow cleavage) mutant (N1023Q). Of particular note, we found that the $\beta$ barrel domain of proEspP $\Delta 1(\mathrm{~N} 1023 \mathrm{Q})$ folded rapidly into a conformation that was resistant to trypsin and PK treatment in detergent solution whereas the $\beta$ barrel domain of proEspP $\Delta 1(\mathrm{~K} 1280 \mathrm{~A})$ 
remained sensitive to degradation. Furthermore, the rapid exposure of the top of the $\beta$ barrel on the cell surface showed that K1280 mutations delay an assembly step that follows the penetration of the $\beta$ barrel far into the OM. It should be emphasized that the assembly step that we identified accelerates, but is not essential for, normal EspP biogenesis. Nevertheless, the observation that the overproduction of the K1280A mutant induces a stress response strongly suggests that the presence of incompletely assembled proteins in the OM and/or the sequestration of Bam complexes by slow assembling OMPs are deleterious and have led to an evolutionary selection for efficient OMP assembly.

Based on our results, we propose a more detailed version of a previously described model for autotransporter biogenesis (Bernstein, 2015). In our model the $\mathrm{C}$ terminus begins to fold into a $\beta$ barrel-like structure in the periplasm that incorporates the $a$-helical linker segment. This partially folded structure is then targeted to the Bam complex, which catalyzes early stages of the membrane insertion process. Subsequently the passenger domain is secreted through a channel composed of the autotransporter $\beta$ barrel domain and the BamA $\beta$ barrel, both of which are in an open conformation (Fig. 11, stage I). The formation of a relatively large hybrid channel would explain the observation that small folded polypeptides can be secreted by the autotransporter pathway (Veiga et al., 2004; Skillman et al., 2005; Sauri et al., 2012; Kang'ethe and Bernstein, 2013). Upon the completion of translocation, the autotransporter $\beta$ barrel closes and dissociates from BamA (Fig. 11, stages II-III). In at least a subset of autotransporters this transition is promoted by a lipid-exposed basic or large polar residue that is located near both the cell surface and the site of closure. The polar residue might become exposed as the result of a conformational change in the $\beta$ barrel that accompanies the termination of translocation or might be exposed at an earlier stage but only exert an effect after the hairpin formed by the passenger domain during translocation is resolved. Although it is possible that this residue facilitates the completion of $\beta$ barrel assembly by forming an interaction with another hydrophilic group, based on our mutational analysis and the pattern of conservation of the residue in distantly related autotransporters produced by highly diverse organisms, we favor an alternative scenario in which it functions by creating a local distortion in the lipid bilayer. Indeed the presence of a lipid facing basic residue in a $\beta$ barrel protein has been shown to distort a model membrane in MD simulations (Fleming et al., 2012). A lysine at position 1280 may promote EspP assembly more effectively than glutamine or glutamate because it has a considerably higher water-to-bilayer transfer free energy in the context of a native $\beta$ barrel protein (Moon and Fleming, 2011) and may therefore create a larger distortion. It is also conceivable that K1280 weakens a hydrophobic interface that forms between the exterior surfaces of the EspP and BamA $\beta$ barrels and thereby accelerates release of the client protein from the Bam complex. In any case, the closing of the EspP $\beta$ barrel is necessary to align the residues that catalyze autocatalytic cleavage. Our crosslinking analysis of the N1023Q mutant suggests that proEspP dissociates from the Bam complex prior to proteolytic maturation (Fig. 11, stage IV). The status of the $\beta$ barrel at this stage is unclear, however, because previous crosslinking studies have suggested that it is released from the Bam complex in a fully folded form after the cleavage reaction is completed (Ieva et al., 2011).

Our study provides several novel insights into the function of the Bam complex and the assembly of bacterial OMPs. First, our results strongly suggest that $\beta$ barrel proteins are not 
released from the Bam complex spontaneously after they partition into the OM, but rather are released in a regulated process that depends on their folded state. Previous work has shown that mutant $\beta$ barrels that are incompletely assembled can remain bound to the Bam complex for significant periods of time (Pavlova et al., 2013a; Lee et al., 2016; Peterson et al., 2017), but the mutants that have been studied appear to be situated on the periplasmic side of the OM in an unintegrated (or partially integrated) state. Second, although our results do not address the exact mechanism by which the Bam complex catalyzes OMP assembly, they indicate that client proteins do not need to be in a fully folded conformation prior to their insertion into the OM. Third, while there is strong evidence that membrane lipids affect the topology of at least some inner membrane proteins in E. coli (Bogdanov et al., 2002), our results suggest that interactions between $\beta$ barrels and hydrophilic or hydrophobic groups of membrane lipids can also play a significant role in OMP assembly in vivo. In any case, in light of our results it should be of great interest to determine if the lipid facing charged residues that are found predominately near the extracellular side of $\beta$ barrel proteins other than autotransporters (Jackups and Liang, 2005; Slusky and Dunbrack, 2013) are likewise required for efficient folding. Indeed one might imagine that the efficient assembly of other "complex" $\beta$ barrel proteins that contain embedded polypeptide segments (e.g, TonB dependent transporters, LptD), also depends on post-insertion interactions.

Finally, our results strongly challenge the view that autotransporters are self-contained secretion systems in which a fully assembled $\beta$ barrel domain mediates a transport function by providing direct evidence that the completion of passenger domain translocation precedes the completion of $\beta$ barrel domain assembly. The data are consistent with but more conclusive than several previous observations, including the finding that the translocation of the EspP passenger domain is initiated before a surface exposed residue in the $\beta$ barrel domain (Y1149) is localized to its final position in the outer leaflet of the OM (Ieva et al., 2011). It is curious, however, that perhaps due to shortcomings in our sequence alignments we could not identify a basic or large polar amino acid near the extracellular side of strand $\beta 11$ in many characterized and putative autotransporters. Of course it is possible that autotransporters that lack such a residue contain another unidentified surface-exposed amino $\operatorname{acid}(\mathrm{s})$ in the $\beta$ barrel domain that performs the same function. Alternatively, the $\beta$ barrel domains of SPATEs and a wide range of other autotransporters may have distinctive sequence or structural properties that require the completion of a post-insertion reaction to maximize the efficiency of assembly.

\section{EXPERIMENTAL PROCEDURES}

\section{Bacterial strains, growth conditions and antisera.}

The E. coli K-12 strains used in these experiments were AD202 (MC4100 ompT::kan) (Akiyama and Ito, 1990), HDB160 (MC4100 ompT::spc bamA::cm pZS21::bamA), HDB161 (MC4100 ompT::spc bamA::cm pZS21::bamA E435A D464A E800A), HDB162 (MC4100 ompT::spc bamA::cm pZS21::bamA D500A), and HDB163 (MC4100 ompT::spc $\triangle c p s B \triangle r f a P)$. Strains HDB160-HDB162 were constructed by introducing either pZS21::bamA (Kim et al., 2007) or mutant derivatives into HDB158 (MC4100 ompT::spc mini- $\lambda$ ) and disrupting the chromosomal copy of bam $A$ by Lambda Red recombination 
(Court et al., 2003). All cultures were grown at $37^{\circ} \mathrm{C}$ in M9 medium containing $0.2 \%$ glycerol and all of the L-amino acids except methionine and cysteine $\left(40 \mu \mathrm{g} \mathrm{ml}^{-1}\right)$ unless otherwise noted. Ampicillin $\left(100 \mu \mathrm{g} \mathrm{ml}^{-1}\right)$ and tetracycline $\left(5 \mu \mathrm{g} \mathrm{ml}^{-1}\right)$ were added as needed. Rabbit polyclonal antisera generated against EspP N- and C-terminal peptides and BamD have been described (Szabady et al., 2005; Pavlova et al., 2013a). A polyclonal antiHA antibody (sc-805) was obtained from Santa Cruz Biotechnology.

\section{Plasmid construction and site-directed mutagenesis.}

Plasmids pJH62, pJH110, pRI22, pRLS5, pET28 encoding EspP 45 and pDULE-Bpa have been described (Farrell et al., 2005; Skillman et al., 2005; Szabady et al., 2005; Ieva and Bernstein, 2009; Pavlova et al., 2013a; Roman-Hernandez et al., 2014). To construct pJH210, which encodes an HA-tagged version of EspP $\Delta 1$, the complementary oligonucleotides 5'pGGCCGCACCGAAAGATGGTTATCCGTACGATGTTCCAGATTACGCAAGCCT-3' and 5'-pGGCCAGGCTTGCGTAATCTGGAACATCGTACGGATAACCATCTTTCGGTGC-3' were cloned into the Eag I site of pJH62. To make plasmid pJH211, which encodes EspP $\Delta 1$ (L3ins), a 800 bp DNA fragment was amplified by PCR using oligonucleotides 5'AGTGATGTAACGCCGGTCATTAC-3' and 5'CACTTTCCAGTCCTTACCAGAGAAGGATTTACCCACATCCAC-3' and pPT17 (Ieva et al., 2011) as a template. The PCR product was then digested with Blp I and Kpn I and cloned into the cognate sites of pJH62. Mutations were introduced into appropriate plasmids by site-directed mutagenesis using the QuikChange II Site-Directed Mutagenesis Kit (Agilent).

\section{Pulse-chase labeling and treatment of intact cells with PK.}

Overnight cultures were washed and diluted into fresh $\mathrm{M} 9$ at $\mathrm{OD}_{550}=0.02$. When the cultures reached $\mathrm{OD}_{550}=0.2$, the synthesis of EspP, EspP $\Delta 1$ or EspP $\Delta 5$ derivatives was induced by the addition of $10 \mu \mathrm{M}$ IPTG. After $30 \mathrm{~min}$, pulse-chase labeling was conducted as described (Ieva and Bernstein, 2009). An equal volume of radiolabeled cells was removed at each time point. In many experiments, radiolabeled cells were pipetted over ice, pelleted $\left(3,000 \times \mathrm{g}, 6 \mathrm{~min}, 4^{\circ} \mathrm{C}\right)$, and resuspended in cold M9 salts. Half of each sample was then treated with PK as described (Ieva and Bernstein, 2009), and proteins in all samples were collected by TCA precipitation. In experiments that did not involve PK treatment, radiolabeled cells were added directly to TCA. Immunoprecipitations were performed as described (Ieva et al., 2008) and proteins were resolved by SDS-PAGE on 8-16\% minigels (Life Technologies). Radioactive proteins were detected using a Fuji BAS-2500 phosphorimager. Percent surface exposure and percent passenger domain cleavage were calculated as described (Peterson et al., 2010).

\section{Solubilization and protease treatment of membrane proteins.}

To assess the effect of mutations on the autocatalytic cleavage of proEspP $\Delta 1$, cells transformed with a derivative of $\mathrm{pJH} 210$ were pulse-labeled and subjected to a 1 min chase. The cells were then pelleted $\left(3000 \times \mathrm{g}, 15 \mathrm{~min}, 4^{\circ} \mathrm{C}\right)$, resuspended in PBS, and disrupted by sonication (Misonix 3000 sonicator, microtip). Unbroken cells were removed by centrifugation $\left(3000 \times \mathrm{g}, 5 \mathrm{~min}, 4^{\circ} \mathrm{C}\right)$ and cell membranes were pelleted in a Beckmann 
TLA 100.2 rotor $100,000 \times \mathrm{g}, 30 \mathrm{~min}, 4^{\circ} \mathrm{C}$ ). The membranes were then resuspended in PBS containing $1 \% \mathrm{DDM}$ and rotated at $4^{\circ} \mathrm{C}$ overnight. After the ultracentrifugation step was repeated to remove insoluble material, immunoprecipitations were performed using an antiHA antibody. To assess the effect of mutations on the folded state of proEspP $\Delta 1$, cells transformed with a derivative of $\mathrm{pJH} 62$ were subjected to pulse-chase labeling and pipetted over ice. Cells were then pelleted $\left(3000 \times \mathrm{g}, 10 \mathrm{~min}, 4^{\circ} \mathrm{C}\right)$, resuspended in an equal volume of cold Tris buffered saline (KD Medical), and divided into aliquots. After the samples were incubated with $100 \mu \mathrm{g} / \mathrm{ml}$ lysozyme $/ 2 \mathrm{mM}$ EDTA for $20 \mathrm{~min}$ on ice, $1 \%$ DDM was added. Samples were then incubated with an appropriate amount of trypsin or PK for $20 \mathrm{~min}$ on ice. Protease digestions were stopped by the addition of $2 \mathrm{mM}$ PMSF, and proteins were collected by TCA precipitation.

\section{Analysis of the sensitivity of the EspP $\beta$ barrel domain to SDS denaturation.}

When $\mathrm{M} 9$ cultures $(50 \mathrm{ml})$ reached $\mathrm{OD}_{550}=0.2$, the synthesis of EspP was induced by the addition of $10 \mu \mathrm{M}$ IPTG. Cells were collected by centrifugation $\left(3000 \times \mathrm{g}, 15 \mathrm{~min}, 4^{\circ} \mathrm{C}\right) 30$ min later and resuspended in PBS at $10 \mathrm{OD}$ units $/ \mathrm{ml}$. A membrane fraction was then isolated as described above. The membrane pellet was resuspended in PBS at $20 \mathrm{OD}$ units $/ \mathrm{ml}$. Aliquots were then mixed with 2x SDS-PAGE sample buffer and heated to a temperature between $25^{\circ} \mathrm{C}$ and $90^{\circ} \mathrm{C}$ for $15 \mathrm{~min}$. The free EspP $\beta$ barrel domain was detected by Western blot.

\section{Site-specific photocrosslinking.}

Cells transformed with pDULE-Bpa and a derivative of pRI22 were grown to $\mathrm{OD}_{550}=0.2$, and the synthesis of EspP was induced by the addition of $200 \mu \mathrm{M}$ IPTG. Pulse-chase labeling and photocrosslinking were performed $30 \mathrm{~min}$ later essentially as described (Ieva et al., 2011; Pavlova et al., 2013b). In brief, at each time point a 2-4 ml aliquot was pipetted into a $15 \mathrm{ml}$ tube over ice, and a $4 \mathrm{ml}$ aliquot was pipetted into a six-well tissue culture plate containing ice and UV irradiated. Both irradiated and non-irradiated cells were pelleted $\left(3500 \times \mathrm{g}, 10 \mathrm{~min}, 4^{\circ} \mathrm{C}\right)$ and resuspended in $1 \mathrm{ml} \mathrm{M} 9$ salts. In some experiments the resuspended cells were immediately TCA precipitated. In other experiments the cells were divided in half, and one half was treated with PK as described above prior to TCA precipitation.

\section{In vitro assembly assays.}

The Bam complex, SurA and urea-denatured EspP $\Delta 5$ and EspP $\Delta 5$ derivatives were purified, the Bam complex was reconstituted into proteoiiposomes, and assembly reactions were performed at $30^{\circ} \mathrm{C}$ as previously described (Hussain and Bernstein, 2018).

\section{Supplementary Material}

Refer to Web version on PubMed Central for supplementary material. 


\section{ACKNOWLEDGMENTS}

We would like to thank Matt Doyle and Rakesh Sikdar for providing helpful comments on the manuscript. This work was supported by the Intramural Research Program of the National Institute of Diabetes and Digestive and Kidney Diseases.

\section{REFERENCES}

Akiyama Y, and Ito K (1990) SecY protein, a membrane-embedded secretion factor of E. coli, is cleaved by the OmpT protease in vitro. Biochem Biophys Res Commun 167: 711-715. [PubMed: 2182019]

Arunmanee W, Pathania M, Solovyova AS, LeBrun AP, Ridley H, Baslé A, et al. (2016). Gramnegative trimeric porins have specific LPS binding sites that are essential for porin biogenesis. Proc Natl Acad Sci USA 113: E5034-E5043. [PubMed: 27493217]

Bakelar J, Buchanan SK, and Noinaj N (2016) The structure of the $\beta$-barrel assembly machinery complex. Science 351: 180-186. [PubMed: 26744406]

Barnard TJ, Dautin N, Lukacik P, Bernstein HD, and Buchanan SK (2007) Autotransporter structure reveals intra-barrel cleavage followed by conformational changes. Nat Struct Mol Biol 14: 12141220. [PubMed: 17994105]

Bernstein HD (2015) Looks can be deceiving: recent insights into the mechanism of protein secretion by the autotransporter pathway. Mol Microbiol 97: 205-215. [PubMed: 25881492]

Bogdanov M, Heacock PN, and Dowhan W (2002) A polytopic membrane protein displays a reversible topology dependent on membrane lipid composition. EMBO J 21: 2107-2116. [PubMed: 11980707]

Bulleris PV, Behrens S, Holst O, and Kleinschmidt JH (2003) Folding and insertion of the outer membrane protein OmpA is assisted by the chaperone Skp and by lipopolysaccharide. J Biol Chem 278: 9092-9099. [PubMed: 12509434]

Chamberlain AK, and Bowie JU (2004) Asymmetric amino acid compositions of transmembrane $\beta$ strands. Protein Sci 13: 2270-2274. [PubMed: 15273317]

Chen R, and Henning U (1996) A periplasmic protein (Skp) of Escherichia coli selectively binds a class of outer membrane proteins. Mol Microbiol 19: 1287-1294. [PubMed: 8730870]

Court DL, Swaminathan S, Yu D, Wilson H, Baker T, Bubunenko M, et al. (2003) Mini-: $\lambda$ a tractable system for chromosome and BAC engineering. Gene 315: 63-69. [PubMed: 14557065]

Dautin N, and Bernstein HD (2007) Protein secretion in Gram-negative bacteria via the autotransporter pathway. Annu Rev Microbiol 61: 89-112. [PubMed: 17506669]

Dautin N, Barnard TJ, Anderson DE, and Bernstein HD (2007) Cleavage of a bacterial autotransporter by an evolutionarily convergent autocatalytic mechnaism. EMBO J 26: 1942-1952. [PubMed: 17347646]

Doerner PA, and Sousa MC (2017) Extreme dynamics in the BamA $\beta$-barrel seam. Biochemistry 56: 3142-3149. [PubMed: 28569500]

Dong H, Xiang Q, Gu Y, Wang Z, Paterson NG, Stansfield PJ, et al. (2014) Structural basis for outer membrane lipopolysaccharide insertion. Nature 511: 52-56. [PubMed: 24990744]

Fairman JW, Noinaj N, and Buchanan SK (2011) The structural biology of $\beta$-barrel membrane proteins: a summary of recent reports. Curr Opin Struct Biol 21: 523-531. [PubMed: 21719274]

Fan E, Chauhan N, Udatha DB, Leo JC, and Linke D (2016) Type V secretion systems in bacteria. Microbiol Spectr 4: doi: 10.1128/microbiolspec.VMBF-0009-2015.

Farrell IS, Toroney R, Hazen JL, Mehl RA, and Chin JW (2005) Photo-cross-linking interacting proteins with a genetically encoded benzophenone. Nat Methods 2: 377-384. [PubMed: 16170867]

Fleming PJ, Freites JA, Moon CP, Tobias DJ, and Fleming KG (2012) Outer membrane phospholipase A in phospholipid bilayers: a model system for concerted computational and experimental investigations of amino acid side chain partitioning into lipid bilayers. Biochim Biophys Acta 1818: 126-134. [PubMed: 21816133] 
Gawarzewski I, DiMaio F, Winterer E, Tschapek B, Smits SHJ, Jose J, et al. (2014) Crystal structure of the transport unit of the autotransporter adhesin involved in diffuse adherence from Escherichia coli. J Struct Biol 187: 20-29. [PubMed: 24841284]

Gessmann D, Chung YH, Danoff EJ, Plummer AM, Sandlin CW, Zaccai NR, et al. (2014) Outer membrane $\beta$-barrel protein folding is physically controlled by periplasmic lipid head groups and BamA. Proc Natl Acad Sci USA 111: 5878-5883. [PubMed: 24715731]

Gu Y, Li H, Dong H, Zeng Y, Zhang Z, Paterson NG, et al. (2016) Structural basis of outer membrane protein insertion by the BAM complex. Nature 531: 64-69. [PubMed: 26901871]

Hagan CL, Kim S, and Kahne D (2010) Reconstitution of outer membrane protein assembly from purified components. Science 328: 890-892. [PubMed: 20378773]

Han L, Zheng J, Wang Y, Liu Y, Sun C, Cao B, et al. (2016) Structure of the BAM complex and its implications for biogenesis of outer-membrane proteins. Nat Struct Mol Biol 23: 192-196. [PubMed: 26900875]

Hussain S, and Bernstein HD (2018) The Bam complex catalyzes efficient insertion of bacterial outer membrane proteins into membrane vesicles of variable lipid composition. J Biol Chem, 293: 2959-2973. [PubMed: 29311257]

Iadanza MG, Higgins AJ, Schiffrin B, Calabrese AN, Brockwell DJ, Ashcroft AE, et al. (2016) Lateral opening in the intact $\beta$-barrel assembly machinery captured by cryo-EM. Nat Commun 7: 12865. [PubMed: 27686148]

Ieva R, Skillman KM, and Bernstein HD (2008) Incorporation of a polypeptide segment into the $\beta$ domain pore during the assembly of a bacterial autotransporter. Mol Microbiol 67: 188-201. [PubMed: 18047580]

Ieva R, and Bernstein HD (2009) Interaction of an autotransporter passenger domain with BamA during its translocation across the bacterial outer membrane. Proc Natl Acad Sci USA 106: 1912019125. [PubMed: 19850876]

Ieva R, Tian P, Peterson JH, and Bernstein HD (2011) Sequential and spatially restricted interactions of assembly factors with an autotransporter $\beta$ domain. Proc Natl Acad Sci USA 108: E383-E391. [PubMed: 21646511]

Jackups R, and Liang J (2005) Interstrand pairing patterns in $\beta$-barrel membrane proteins: the positiveoutside rule, aromatic rescue, and strand registration prediction. J Mol Biol 354: 979-993. [PubMed: 16277990]

Jimenez-Morales D, and Liang J (2011) Pattern of amino acid substitutions in transmembrane domains of $\beta$-barrel membrane proteins for detecting remote homologs in bacteria and mitochondria. PLoS One 6: e26400. [PubMed: 22069449]

Junker M, Besingi RN, and Clark PL (2009) Vectorial transport and folding of an autotransporter virulence protein during outer membrane secretion. Mol Microbiol 71: 1323-1332. [PubMed: 19170888]

Kang'ethe W, and Bernstein HD (2013) Charge-dependent secretion of an intrinsically disordered protein via the autotransporter pathway. Proc Natl Acad Sci USA 110: E4246-E4255. [PubMed: 24145447]

Kim S, Malinverni JC, Sliz P, Silhavy TJ, Harrison SC, and Kahne D (2007) Structure and function of an essential component of the outer membrane protein assembly machine. Science 317: 961-964. [PubMed: 17702946]

Lazar SW, and Kolter R (1996) SurA assists the folding of Escherichia coli outer membrane proteins J Bacteriol 178: 1770-1773. [PubMed: 8626309]

Lee J, Xue M, Wzorek JS, Wu T, Grabowicz M, Gronenberg LS, et al. (2016) Characterization of a stalled complex on the $\beta$-barrel assembly machine. Proc Natl Acad Sci USA 113: 8717-8722. [PubMed: 27439868]

Malinverni JC, Werner J, Kim S, Sklar JG, Kahne D, Misra R, et al. (2006) YfiO stabilizes the YaeT complex and is essential for outer membrane protein assembly in Escherichia coli. Mol Microbiol 61: 151-164. [PubMed: 16824102]

Moon CP, and Fleming KG (2011) Side-chain hydrophobicity scale derived from transmembrane protein folding into lipid bilayers. Proc Natl Acad Sci USA 108: 10174-10177. [PubMed: 21606332] 
Ni D, Wang Y, Yang X, Zhou H, Hou X, Cao B, et al. (2014) Structural and functional analysis of the $\beta$-barrel domain of BamA from Escherichia coli. FASEB J 28: 2677-2685. [PubMed: 24619089]

Noinaj N, Kuszak AJ, Gumbart JC, Lukacik P, Chang H, Easley NC, et al. (2013) Structural insight into the biogenesis of $\beta$-barrel membrane proteins. Nature 501: 385-390. [PubMed: 23995689]

Noinaj N, Kuszak AJ, Balusek C, Gumbart JC, and Buchanan SK (2014) Lateral opening and exit pore formation are required for BamA function. Structure 22: 1055-1062. [PubMed: 24980798]

Oomen CJ, van Ulsen P, van Gelder P, Feijen M, Tommassen J, and Gros P (2004) Structure of the translocator domain of a bacterial autotransporter. EMBO J 23: 1257-1266. [PubMed: 15014442]

Qiao S, Luo Q, Zhao Y, Zhang XC, and Huang Y (2014) Structural basis for lipopolysaccharide insertion in the bacterial outer membrane. Nature 511: 108-111. [PubMed: 24990751]

Pavlova O, Peterson JH, Ieva R, and Bernstein HD (2013a) Mechanistic link between $\beta$ barrel assenbly and the initiation of autotransporter secretion. Proc Natl Acad Sci USA 110: E938-E947. [PubMed: 23431155]

Pavlova O, Ieva R, and Bernstein HD (2013b) Monitoring the assembly of a secreted bacterial virulence factor using site-specific crosslinking. J Vis Exp e51217. [PubMed: 24378574]

Peterson JH, Tian P, Ieva R, Dautin N, and Bernstein HD (2010) Secretion of a bacterial virulence factor is driven by the folding of a C-terminal segment. Proc Natl Acad Sci USA 107: 1773917744. [PubMed: 20876094]

Peterson JH, Plummer AM, Fleming KG, and Bernstein HD (2017) Selective pressure for rapid membrane integration constrains the sequence of bacterial outer membrane proteins. Mol Microbiol 106: 777-792 [PubMed: 28941249]

Pohlner J, Halter R, Beyreuther K, and Meyer TF (1987) Gene structure and extracellular secretion of Neisseria gonorrhoeae IgA protease. Nature 325: 458-462. [PubMed: 3027577]

Roman-Hernandez G, Peterson JH, and Bernstein HD (2014) Reconstitution of bacterial autotransoprter assembly using purified components. Elife 3: e04234. [PubMed: 25182416]

Rouvière PE, and Gross CA (1996) SurA, a periplasmic protein with peptidyl-prolyl isomerase activity, participates in the assembly of outer membrane porins. Genes Dev 10: 3170-3182. [PubMed: 8985185]

Sauri A, ten Hagen-Jongman C, van Ulsen P, and Luirink J (2012) Estimating the size of the active translocation pore of an autotransporter. J Mol Biol 416: 335-345. [PubMed: 22227392]

Schäfer U, Beck K, and Müller M (1999) Skp, a molecular chaperone of Gram-negative bacteria, is required for the formation of soluble periplasmic intermediates of outer membrane proteins. J Biol Chem 274: 24567-24574. [PubMed: 10455120]

Schiffrin B, Calabrese AN, Higgins AJ, Humes JR, Ashcroft AE, Kalli AC, et al. (2017) Effects of periplasmic chaperones and membrane thickness on BamA-catalyzed outer-membrane protein folding. J Mol Biol 429: 3776-3792. [PubMed: 28919234]

Sikdar R, Peterson JH, Anderson DE, and Bernstein HD (2017) Folding of a bacterial integral outer membrane protein is initiated in the periplasm. Nat Commun 8: 1309. [PubMed: 29101319]

Skillman KM, Barnard TJ, Peterson JH, Ghirlando R, and Bernstein HD (2005) Efficient secretion of a folded protein domain by a monomeric bacterial autotransporter. Mol Microbiol 58: 945-958. [PubMed: 16262782]

Sklar JG, Wu T, Gronenberg LS, Malinverni JC, Kahne D, and Silhavy TJ (2007) Lipoprotein SmpA is a component of the YaeT complex that assembles outer membrane proteins in Escherichia coli. Proc Natl Acad Sci USA 104: 6400-6405. [PubMed: 17404237]

Slusky JS, and Dunbrack RL, Jr. (2013) Charge asymmetry in the proteins of the outer membrane. Bioinformatics 29: 2122-2128. [PubMed: 23782617]

Szabady RL, Peterson JH, Skillman KM, and Bernstein HD (2005) An unusual signal peptide facilitates late steps in the biogenesis of a bacterial autotransporter. Proc Natl Acad Sci USA 102: 221-226. [PubMed: 15615856]

Ulmschneider MB, and Sansom MS (2001) Amino acid distributions in integral membrane protein structures. Biochim Biophys Acta 1512: 1-14. [PubMed: 11334619]

van den Berg B (2010) Crystal structure of a full-length autotransporter. J Mol Biol 396: 627-633. [PubMed: 20060837] 
Veiga E, deLorenzo V, and Fernández LA (2004) Structural tolerance of bacterial autotransporters for folded passenger domains. Mol Microbiol 52: 1069-1080. [PubMed: 15130125]

Voulhoux R, Bos MP, Geurtsen J, Mols M, and Tommassen J (2003) Role of a highly conserved bacterial protein in outer membrane protein assembly. Science 299: 262-266. [PubMed: 12522254]

Webb CT, Heinz E, and Lithgow T (2012) Evolution of the $\beta$-barrel assembly machinery. Trends Microbiol 20: 612-620. [PubMed: 22959613]

Whitfield C (2006) Biosynthesis and assembly of capsular polysaccharides in Escherichia coli. Annu Rev Biochem 75: 39-68. [PubMed: 16756484]

Wu T, Malinverni J, Ruiz N, Kim S, Silhavy TJ, and Kahne D (2005) Identification of a multicomponent complex required for outer membrane biogenesis in Escherichia coli. Cell 121: 23-245.

Yethon JA, Heinrichs DE, Monteiro MA, Perry MB, and Whitfield C (1999) Involvement of waaY, $w a a Q$, and waaP in the modification of Escherichia coli lipopolysaccharide and their role in the formation of a stable outer membrane. J Biol Chem 273: 26310-26316.

Zhai Y, Zhang K, Huo Y, Zhu Y, Zhou Q, Lu J, et al. (2011) Autotransporter passenger domain secretion requires a hydrophobic cavity at the extracellular entrance of the $\beta$-domain pore. Biochem J 435: 577-587. [PubMed: 21306302] 
A

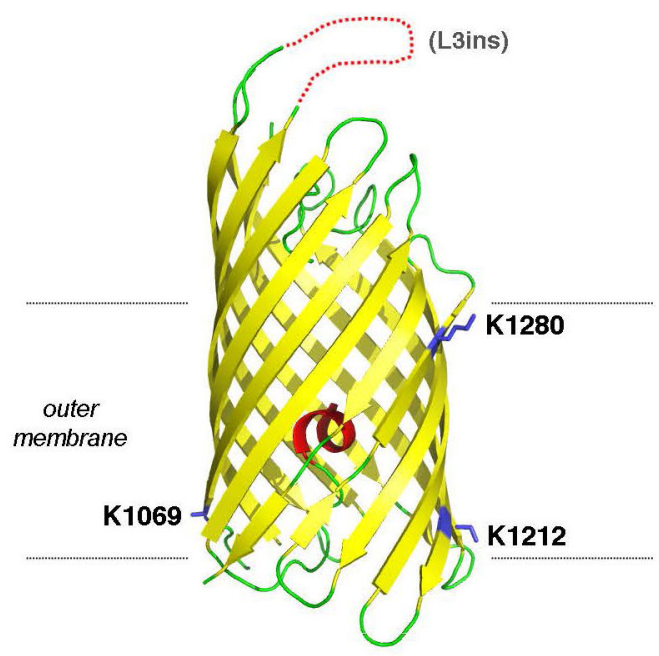

B

$\begin{array}{ll}\text { Escherichia coli (ESpP) } & \text { VRFGLEFEKSAFGKY-NVDNAVNANFKYSF } \\ \text { Helicobacter mustelae (HSr) } & \text { HRFYFDFERSFGGKI-ITDYQFNIGYRYNF } \\ \text { Pseudomonas syringae } & \text { VYWGADYNRDLNSHD-SSGANASLGVRLAW } \\ \text { Pseudomonas fluorescens } & \text { LSMHADLERSVGKNI-KQPLGVNVGLRYAF } \\ \text { Haemophilus influenzae (Hap) } & \text { FQISAFISKSQGSQL-GKQQNVGVKLGYRW } \\ \text { Neisseria lactamica } & \text { LYADARCEKSFDSNK-HHGCQGTVGMKYSWK } \\ \text { Haemophilus haemolyticus } & \text { LYADARYEKSFDSNR-HKGYQGTVGVKYSWK } \\ \text { Kingella denitrificans } & \text { LYGDARYERNLGGAK-RDGYRGTVGFKYTWK } \\ \text { Haemophilus parasuis } & \text { VYADTRYERNLGAK-REGYRGTVGFKTWK } \\ \text { Moraxella cuniculi } & \text { VYADARYEREFGGSAKRDGYRGTVGWKTWK } \\ \text { Fusobacterium nucleatum } & \text { VYTDLRYERSFKSNPKHNGYRGTVGLKYTF } \\ & \\ \text { Kluyvera georgiana } & \\ \text { Histophilus somni } & \text { VYADGRYEHSFTSDK-RESYKGTVGLKFTWK } \\ \text { Eikenella corrodens } & \text { VYADVRYEHSLSGTK-HEGYRGTVGFKYTWK } \\ \text { EScherichia coli (Ag43) } & \text { VYGDARYQHNFGSTS-RHGYRGSVGFKTWK } \\ \text { Bartonella henselae (Arp) } & \text { LGVQAGYAHSVSGSS-AEGYNGQATLNVTF } \\ \text { Neisseria meningitidis } & \text { LHADINYQHKLQKAG-VSGINFSAGMRYQF } \\ \text { Yersinia pestis (YapH) } & \text { IYADARYEQSLSGTK-HGGYKGSIGIKYSW } \\ \text { Shigella flexneri (ICSA) } & \text { LNLWGNIGQQVGNKG-YSETSVVLGVKYNF } \\ \text { Citrobacter rhodentium } & \text { LSIWGNVSQQLGNNS-YRDTQGILGVKYTF } \\ \text { Salmonella typhimurium (ApeE) } & \text { VSLWGNVGQQVGDQG-YSDTSAMIGIKASF } \\ & \end{array}$

Fig. 1.

Location of surface-exposed lysine residues in the $\operatorname{EspP} \beta$ barrel domain. A. The crystal structure of the free $\beta$ barrel domain of EspP (Barnard et al., 2007) and the positions of the three surface-exposed lysine residues are shown. The small $a$-helical segment that remains inside the $\beta$ barrel following proteolytic maturation and the site of a peptide insertion in loop 3 that is described in this study (L3ins) are shown in red. B. The C-terminal 29 residues of the EspP $\beta$ barrel domain (residues 1272-1300) that comprise $\beta$ strands 11 and 12 and the equivalent regions of known autotransporters and predicted autotransporters encoded in the genomes of a variety of organisms are illustrated. The names of characterized 
autotransporters appear in parentheses. The position of a conserved basic/large polar residue (K1280 in EspP) is shown in red. 


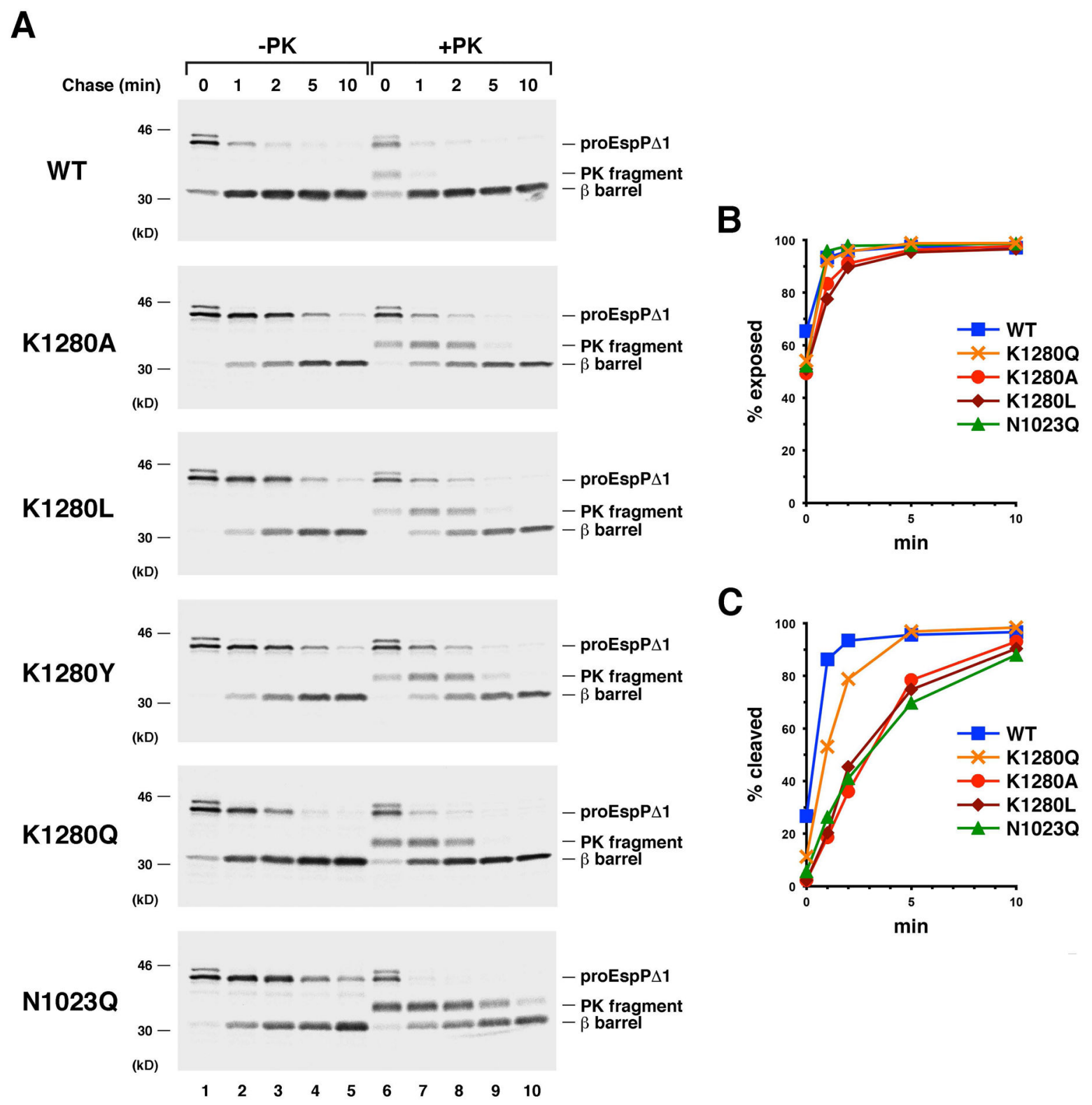

Fig. 2.

Residue K1280 promotes the efficient assembly of EspP. A. AD202 transformed with pJH62 $\left(\mathrm{P}_{\text {trc }}\right.$-espPA1) or a pJH62 derivative encoding the indicated EspP $\Delta 1$ mutant were subjected to pulse-chase labeling after the addition of IPTG. Half of the cells were treated with PK, and immunoprecipitations were conducted using an antiserum generated against an EspP Cterminal peptide. Lanes 1-5, untreated samples (-PK); lanes 6-10, PK treated samples $(+\mathrm{PK})$. The percentage of the passenger domain that was surface exposed or released from the $\beta$ barrel domain by proteolytic cleavage or at each time point is plotted in $\mathrm{B}$ and $\mathrm{C}$. The K1280Y mutation exerted essentially the same effect on EspP $\Delta 1$ assembly as the K1280A and $\mathrm{K} 1280 \mathrm{~L}$ mutations, but the data were not plotted to maintain clarity. 


\section{-IPTG}
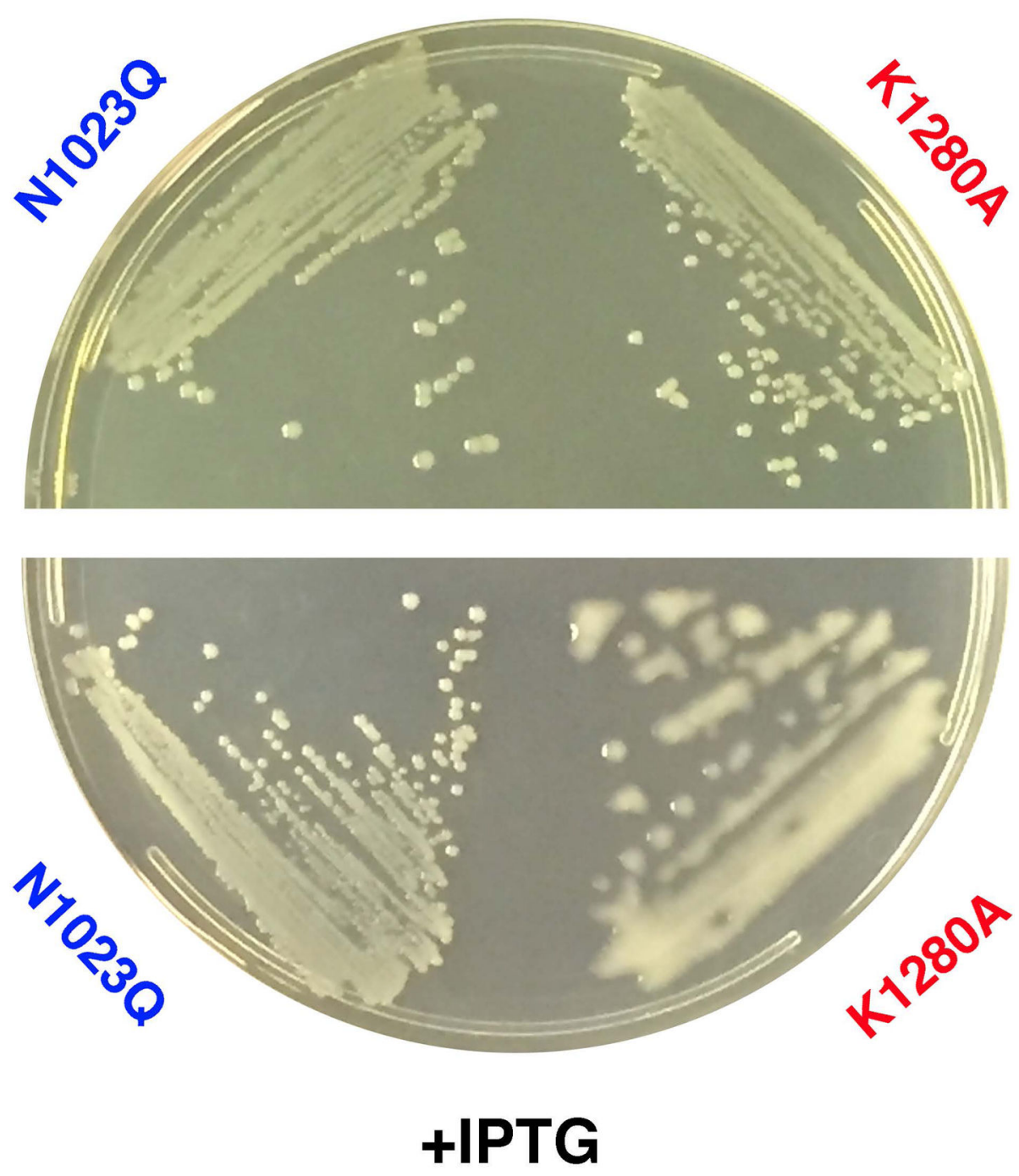

Fig. 3.

Overproduction of the EspP $\Delta 1$ (K1280A) mutant leads to the formation of mucoid colonies. AD202 transformed with a pJH62 derivative encoding EspP $\Delta 1$ (K1280A) or EspP $\Delta 1$ (N1023Q) were streaked on LB agar containing $100 \mu \mathrm{g} / \mathrm{ml}$ ampicillin and either no IPTG or $100 \mu \mathrm{M}$ IPTG and incubated at $37^{\circ} \mathrm{C}$. 


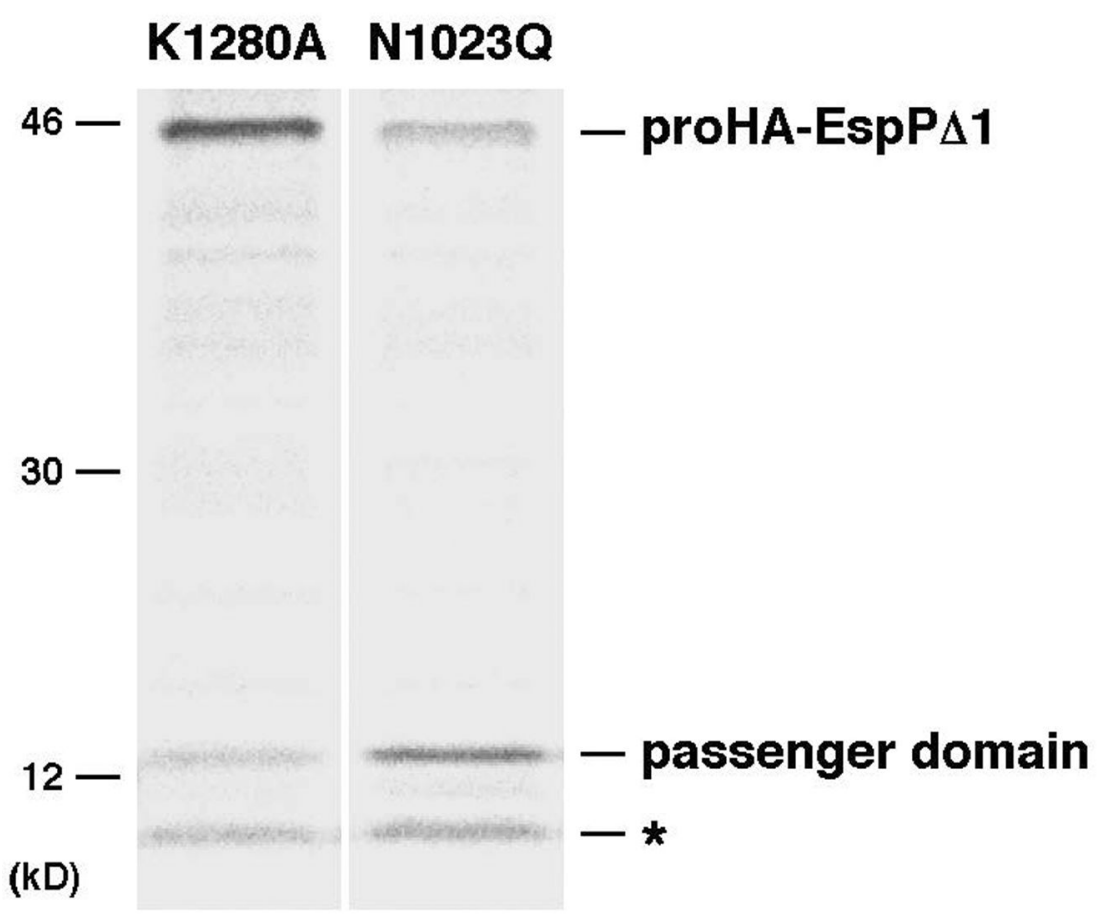

Fig. 4.

The EspP $\Delta 1$ (K1280A) mutant does not undergo efficient self-cleavage in solution. AD202 transformed with a derivative of $\mathrm{pJH} 210\left(\mathrm{P}_{\text {trc }}-H A\right.$-espPAI) derivative encoding HA-tagged $\operatorname{EspP} \Delta 1(\mathrm{~K} 1280 \mathrm{~A})$ or EspP $\Delta 1$ (N1023Q) were pulse-labeled and subjected to a 1 min chase following the addition of IPTG. A membrane fraction was isolated and incubated in PBS containing 1\% DDM overnight. Immunoprecipitations were then conducted using an antiHA antibody. A non-specific band that cross-reacted with the antibody is denoted by an asterisk. 


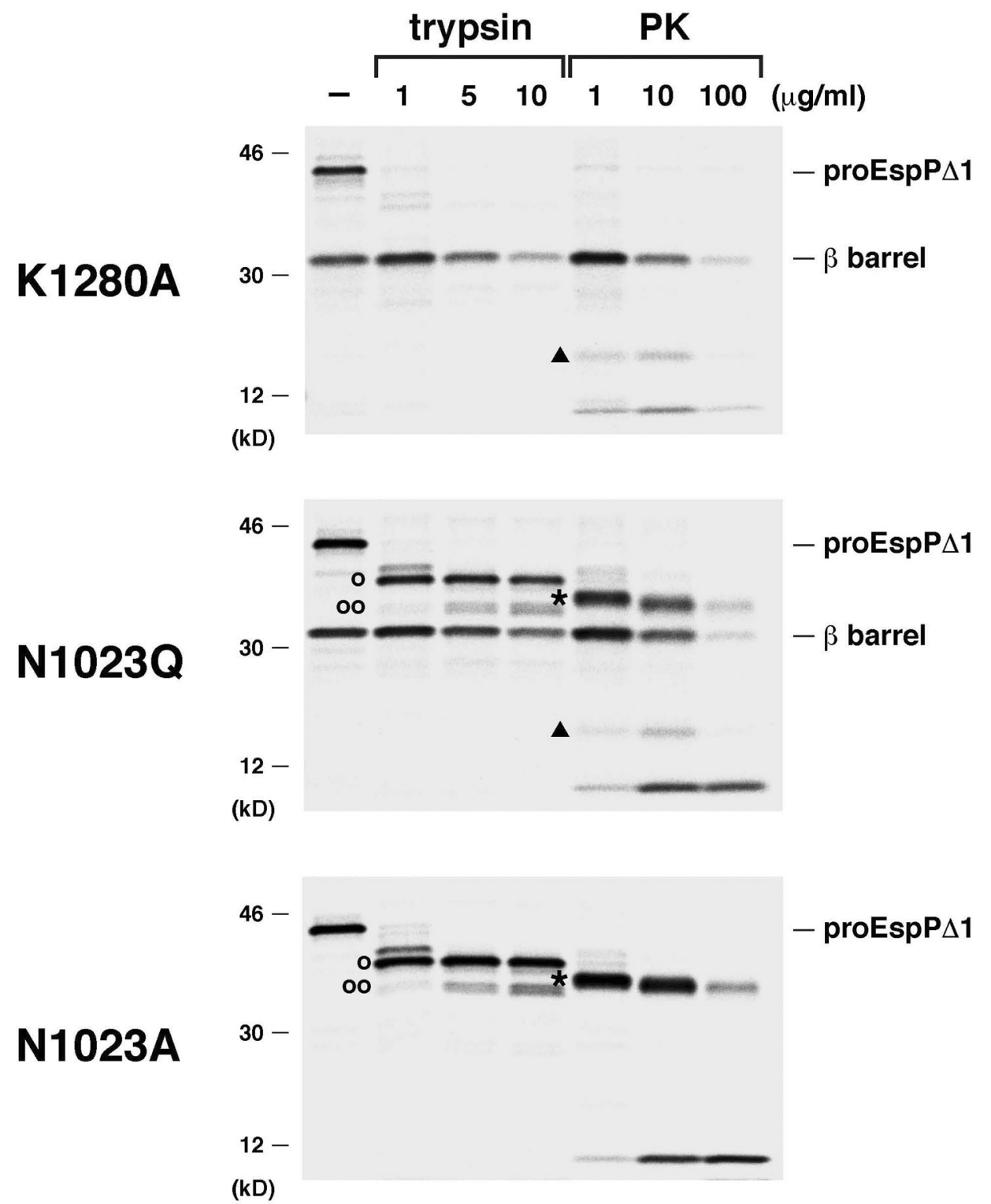

Fig. 5.

Solubilized proEspP $\Delta 1$ (K1280A) is digested by low concentrations of trypsin and PK. AD202 transformed with a derivative of pJH62 encoding the indicated EspP $\Delta 1$ mutant were pulse-labeled and subjected to a $1 \mathrm{~min}$ chase following the addition of IPTG. Permeabilized cells were incubated with DDM and the indicated amount of either trypsin or PK. immunoprecipitations were then performed using an anti-EspP C-terminal peptide antiserum. Tryptic fragments of proEspP $\Delta 1$ (o and oo), a PK fragment of proEspP $\Delta 1\left(^{*}\right)$, and a PK fragment of the free $\beta$ barrel domain $(\Delta)$ are denoted. 


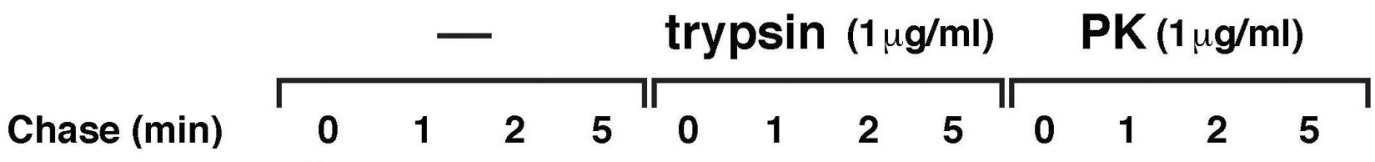

K1280A

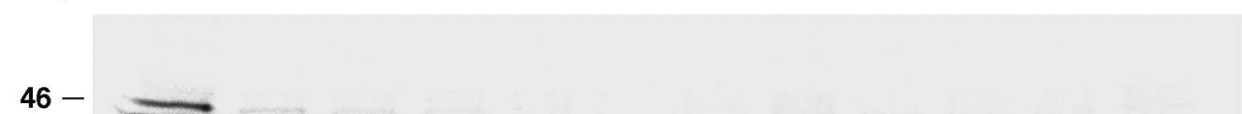

(kD)

N1023Q

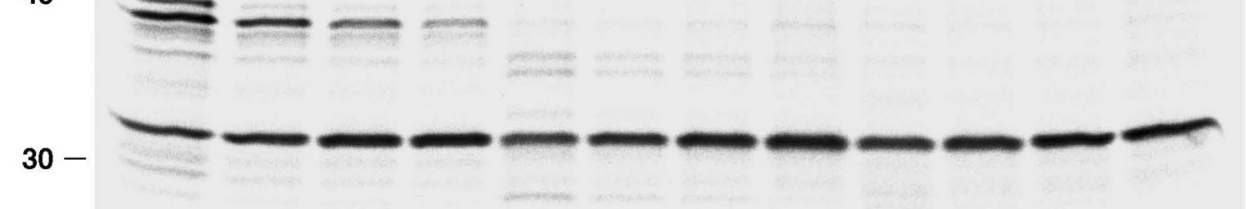

$-\operatorname{proEspP} \Delta 1$

$-\beta$ barrel

$12-$

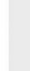

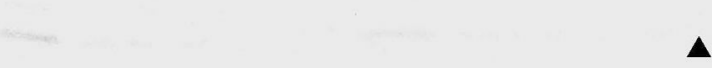

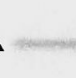
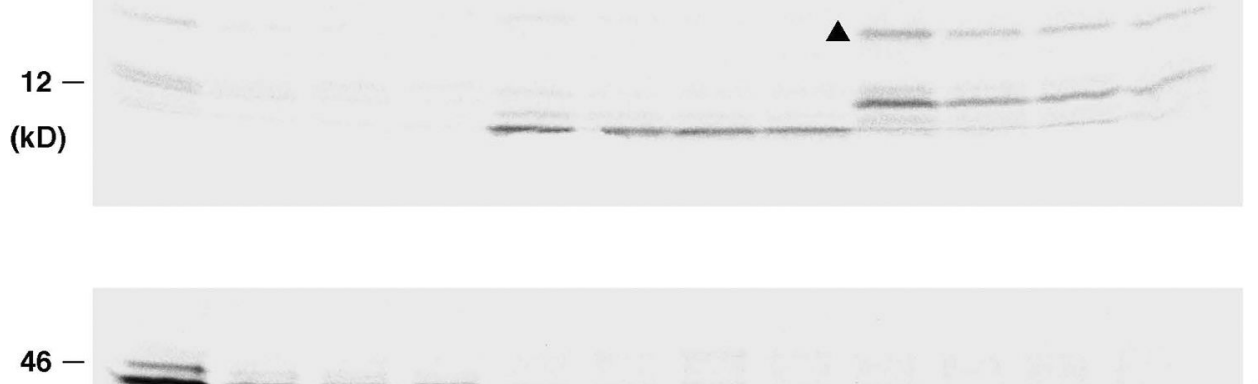

46
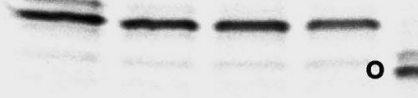

$30-$
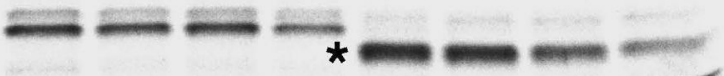

$-\operatorname{proEspP} \Delta 1$

$12-$

(kD)

\section{Fig. 6.}

Solubilized proEspP $\Delta 1$ (K1280A) remains sensitive to protease treatment for a prolonged period. AD202 transformed with a pJH62 derivative encoding EspP $\Delta 1$ (K1280A) or EspP $\Delta 1$ (N1023Q) were subjected to pulse-chase labeling following the addition of IPTG. Permeabilized cells were incubated with DDM and either trypsin or PK $(1 \mu \mathrm{g} / \mathrm{ml})$. immunoprecipitations were then performed using an anti-EspP C-terminal peptide antiserum. A tryptic fragment of proEspP $\Delta 1$ (o), a PK fragment of proEspP $\Delta 1(*)$, and a PK fragment of the free $\beta$ barrel domain $(\Delta)$ are denoted. 


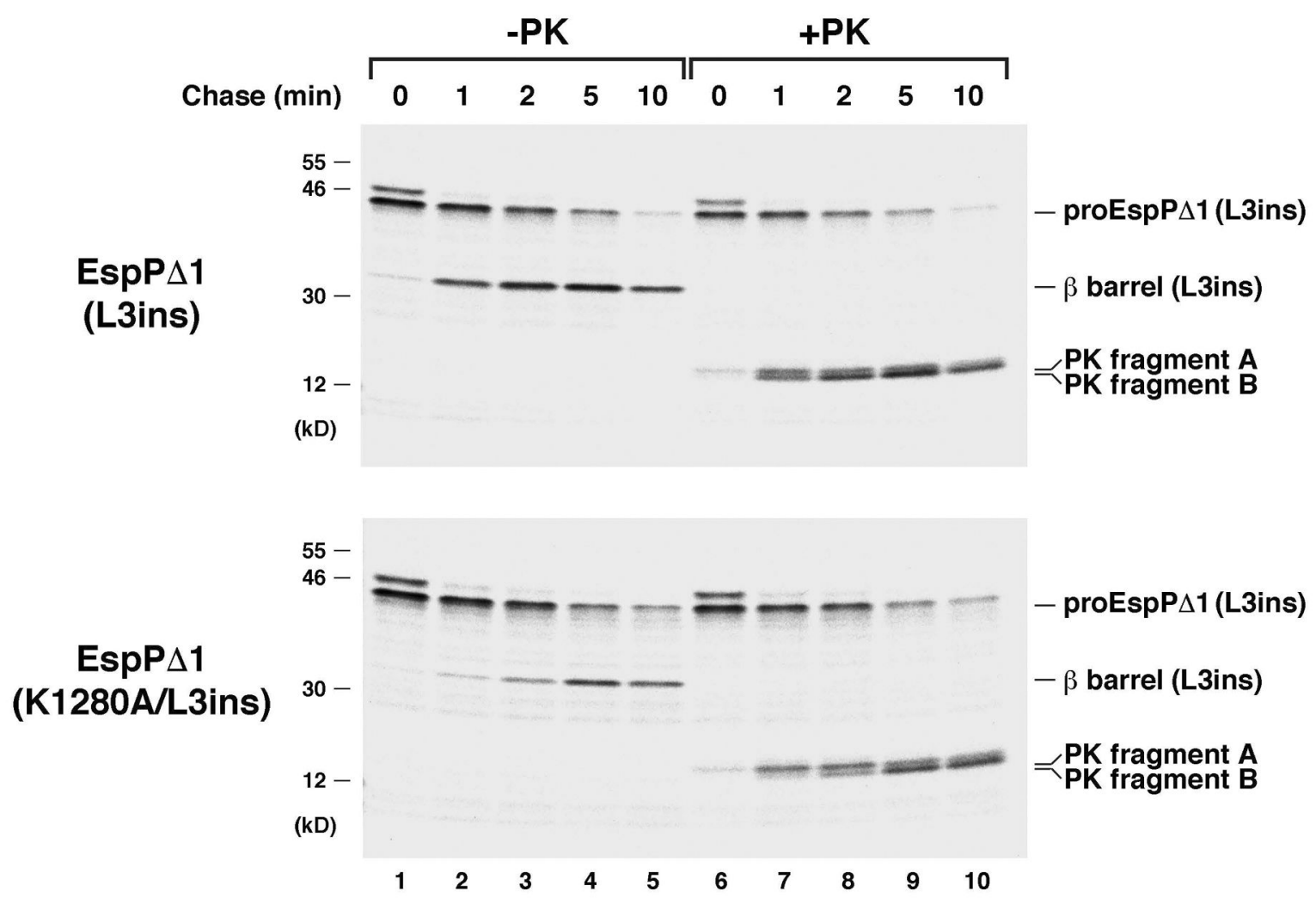

Fig. 7.

The EspP $\Delta 1$ (K1280A) $\beta$ barrel is rapidly exposed on the cell surface. AD202 transformed with a pJH211 [ $\mathrm{P}_{\text {trc }}-\operatorname{espP} \Delta 1$ (L3ins)] or a derivative encoding EspP $\Delta 1$ (K1280A/L3ins) were subjected to pulse-chase labeling after the addition of IPTG. Half of the cells were treated with PK, and immunoprecipitations were performed using an anti-EspP C-terminal peptide antiserum. Lanes 1-5, untreated samples (-PK); lanes 6-10, PK treated samples (+PK). 
A
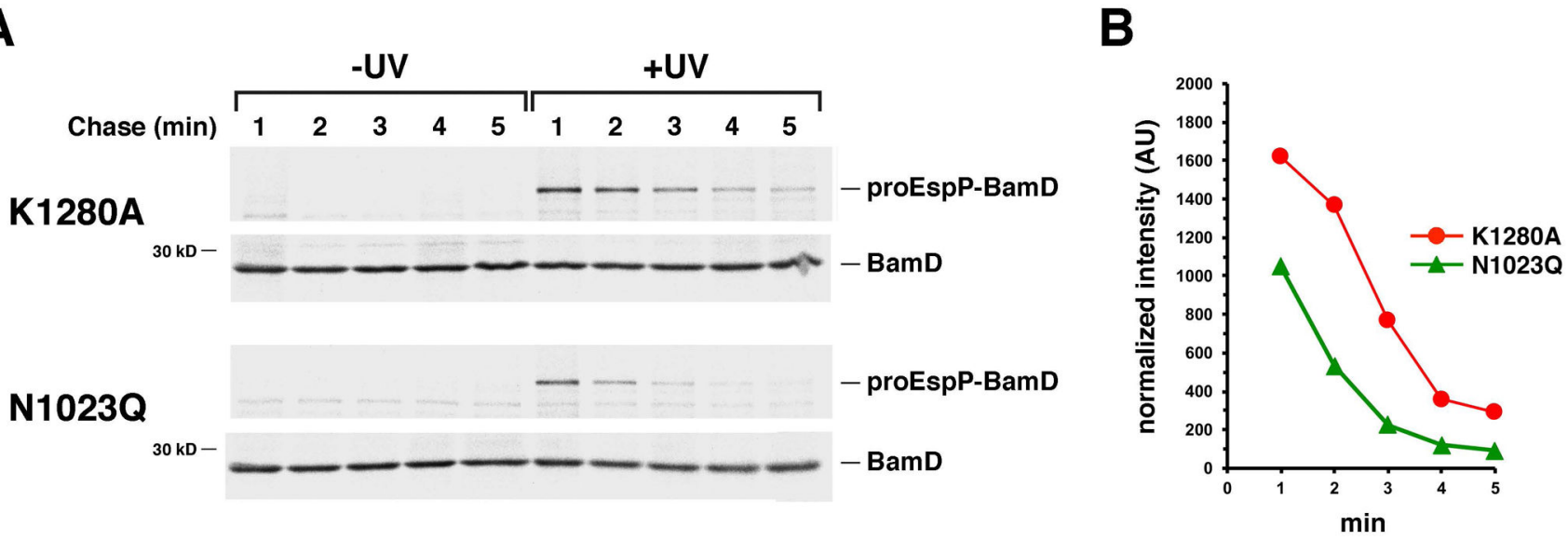

Fig. 8.

EspP (K1280A) forms a prolonged interaction with the Bam complex. A. AD202 transformed with pDULE-Bpa and a derivative of pRI22 encoding EspP (K1280A) or EspP (N1023Q) with an amber mutation at position 1214 were subjected to pulse-chase labeling after the addition of IPTG. One aliquot of cells was UV-irradiated while an equal aliquot was left untreated. Immunoprecipitations were then conducted using an anti-BamD antiserum. (Complementary immunoprecipitations conducted using an anti-EspP C-terminal peptide antiserum are shown in Fig. S6). B. The intensity of the proEspP-BamD signal in A (in arbitrary units, $\mathrm{AU}$ ) was normalized to the intensity of the BamD signal in the same sample. 
A

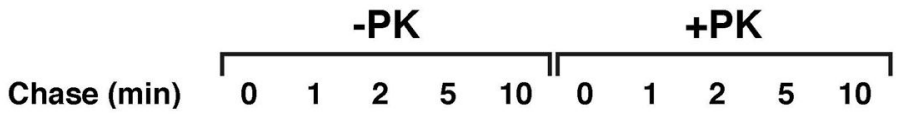

WT
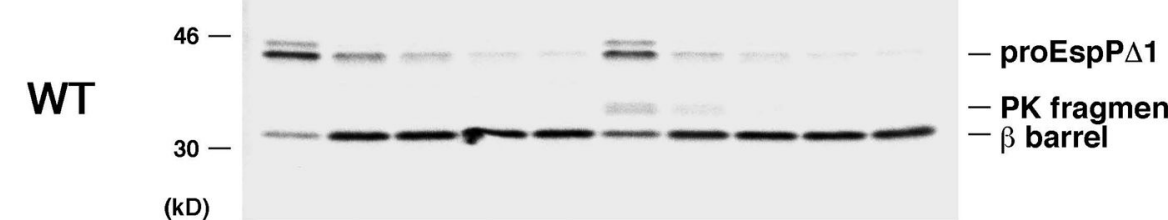

- PK fragment

$-\beta$ barrel

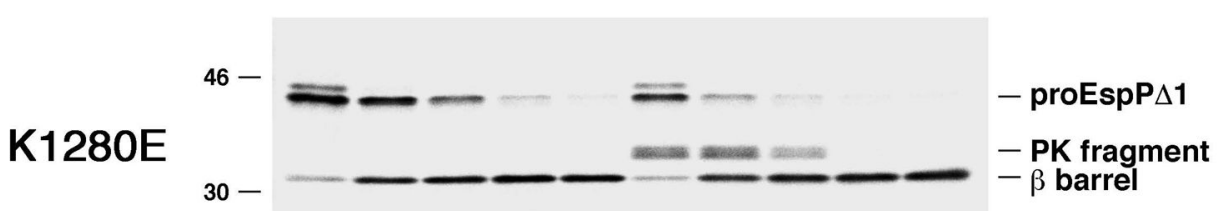

(kD)

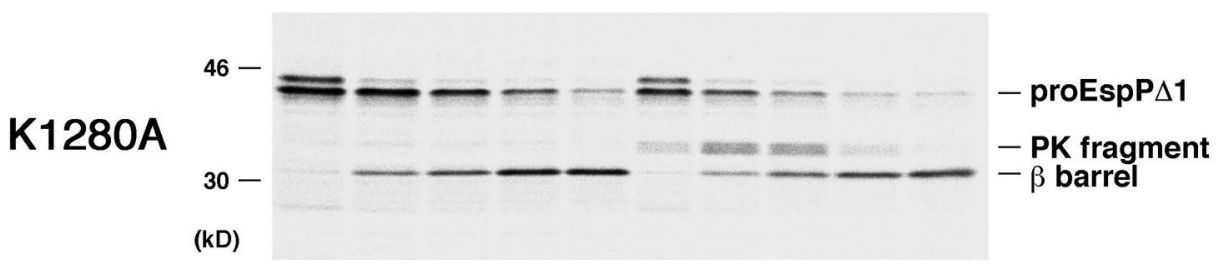

B

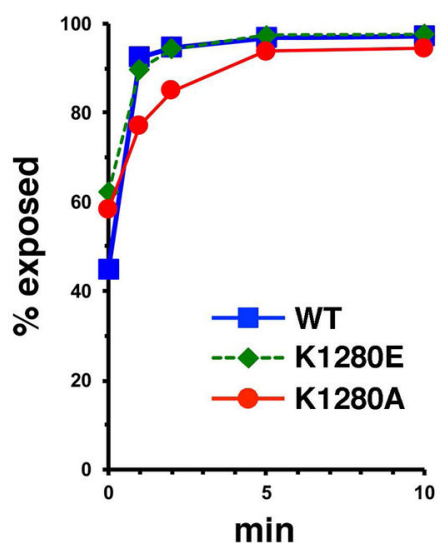

C

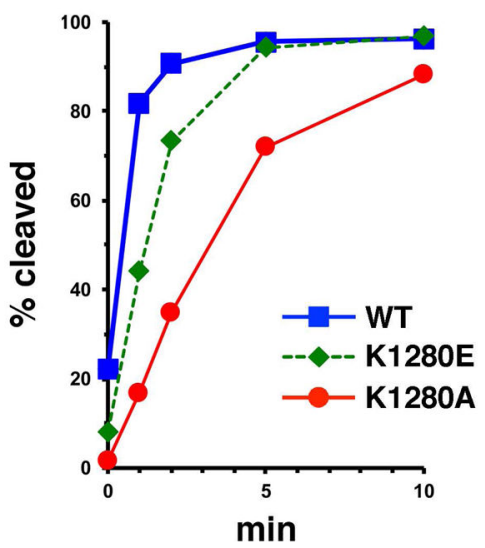

Fig. 9.

The mutation of K1280 to an acidic residue only modestly affects the assembly of EspP $\Delta 1$. A. AD202 transformed with pJH61 ( $\mathrm{P}_{\text {trc }}$-espP) or a pJH61 derivative encoding the indicated $\operatorname{EspP} \Delta 1$ mutant were subjected to pulse-chase labeling after the addition of IPTG. Half of the cells were treated with PK, and immunoprecipitations were conducted using an antiEspP C-terminal peptide antiserum. The percentage of the passenger domain that was surface exposed or released from the $\beta$ barrel domain by proteolytic cleavage or at each time point is plotted in $\mathrm{B}$ and $\mathrm{C}$. 
A

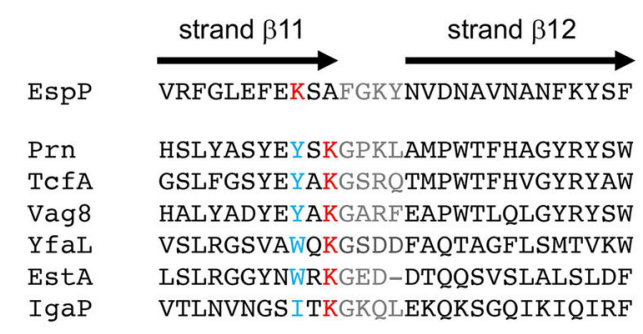

B
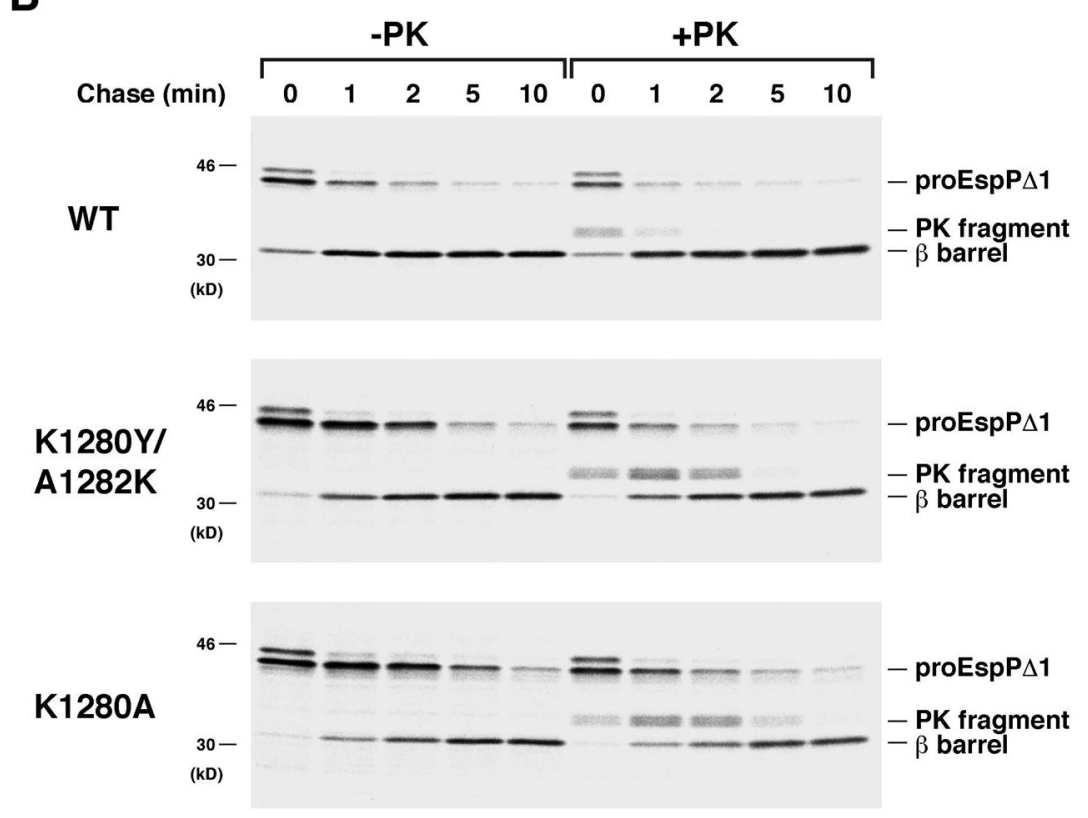

C
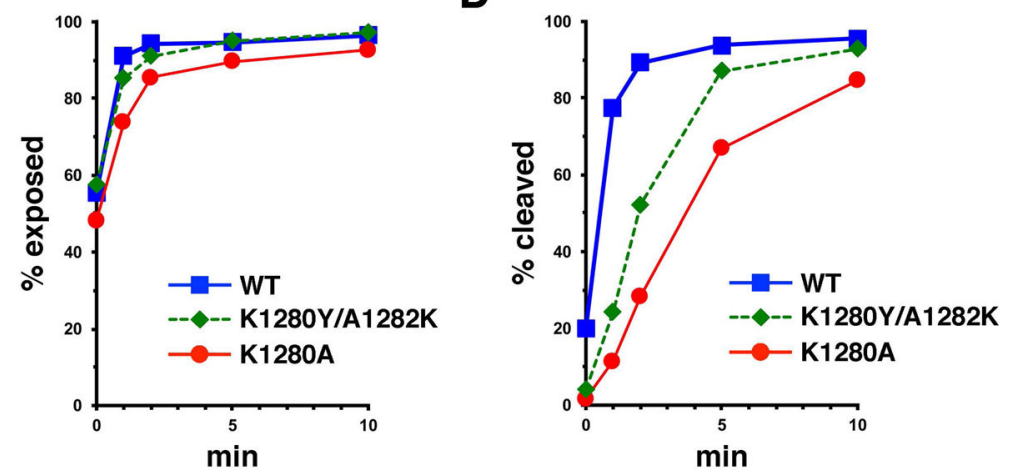

Fig. 10.

The introduction of a lysine at position 1282 partially replaces the function of EspP residue K1280. A. The C-terminal 29 residues of the EspP $\beta$ barrel domain (residues 1272-1300) that comprise $\beta$ strands 11 and 12 and the equivalent regions of autotransporters produced by Bordetella pertussis (Prn, TcfA and Vag8), E. coli (YfaL), Pseudomonas aeruginosa (EstA) and Neisseria gonorrhoeae (IgaP) are illustrated. The K1280 residue in EspP and predicted surface-exposed lysine residues located in the same $\beta$ strand are shown in red. In the other proteins a large hydrophobic residue is located at the same position as K1280 (cyan). B. AD202 transformed with pJH61 $\left(\mathrm{P}_{t r c}-e s p P\right)$ or a pJH61 derivative encoding the 
indicated EspP $\Delta 1$ mutant were subjected to pulse-chase labeling after the addition of IPTG. Half of the cells were treated with PK, and immunoprecipitations were conducted using an anti-EspP C-terminal peptide antiserum. The percentage of the passenger domain that was surface exposed or released from the $\beta$ barrel domain by proteolytic cleavage or at each time point is plotted in $\mathrm{C}$ and $\mathrm{D}$. 


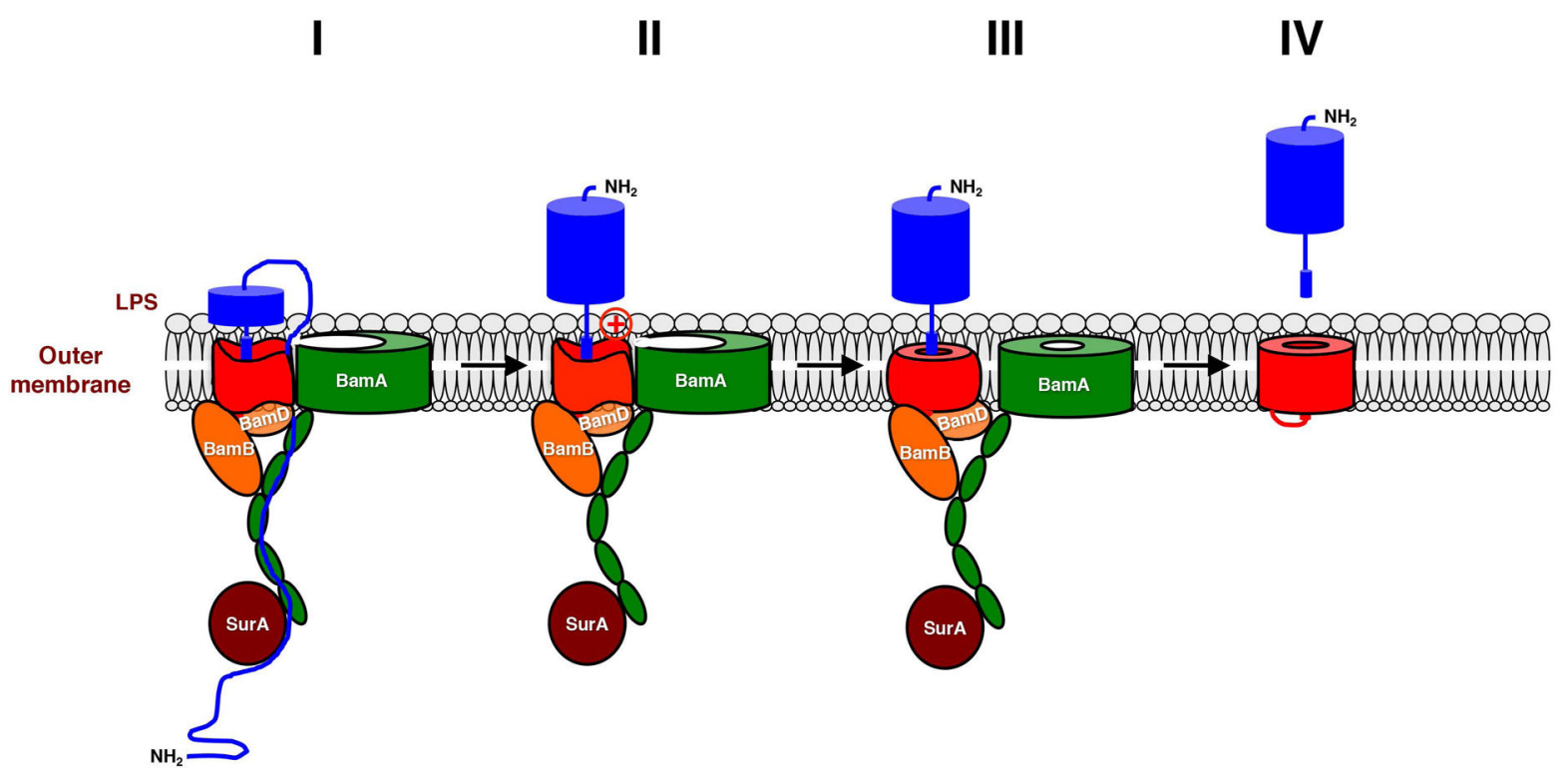

Fig. 11.

Model of EspP assembly. After the $\mathrm{C}$ terminus of EspP folds into a $\beta$ barrel-like structure that incorporates the $\mathrm{a}$-helical linker in the periplasm, the Bam complex catalyzes the insertion of the $\beta$ barrel domain (red) into the OM. The passenger domain (blue) is then translocated across the OM through a channel comprised of the covalently linked $\beta$ barrel domain and the $\beta$ barrel of BamA, both in an open conformation (I). Following the completion of translocation (II), residue K1280 creates a local distortion in the lipid bilayer that facilitates the closing of the $\beta$ barrel domain (III). Ultimately the $\beta$ barrel domain is released from the Bam complex into the lipid bilayer and the passenger domain is cleaved in an autocatalytic reaction (IV). Some of the available evidence (see Ieva et al., 2011) suggests that the proteolytic maturation of the protein occurs prior to the release of the $\beta$ barrel domain from the Bam complex. 